Review Article

\title{
Obesity Prevention: A Systematic Review of Setting-Based Interventions from Nordic Countries and the Netherlands
}

\author{
Jacqueline Panter $\mathbb{D}^{D}$, Pernille Tanggaard Andersen, Arja R. Aro, and Anastasia Samara
}

Unit for Health Promotion Research, University of Southern Denmark, Esbjerg, Denmark

Correspondence should be addressed to Anastasia Samara; asamara@health.sdu.dk

Received 16 July 2017; Revised 6 December 2017; Accepted 25 February 2018; Published 1 April 2018

Academic Editor: R. Prager

Copyright (C) 2018 Jacqueline Panter et al. This is an open access article distributed under the Creative Commons Attribution License, which permits unrestricted use, distribution, and reproduction in any medium, provided the original work is properly cited.

\begin{abstract}
Aim. Effective evidence-based interventions have an important role in obesity prevention. Our aim was to present a qualitative synthesis of setting-based health promotion interventions on obesity, from Nordic countries and the Netherlands. Methods. A systematic review of the literature was completed for studies in the community, schools, and worksite, with BMI as an outcome. A descriptive analysis was completed for all full-text articles meeting the inclusion criteria. Results. Thirty-three articles were identified: 7 whole of community, 3 worksite, and 23 school-based interventions. The studies were largely quasiexperimental in design (21/33), with follow-up from 4 months to 8 years. The explicit use of theory was not featured in many of the studies (20/33). No consistent direction for BMI change could be identified in the whole of community interventions ( $2 / 7$ positive, $2 / 7$ negative, and $3 / 7$ no effect) and no effect for worksite (3/3 no effect) or many of the school-based interventions (1/23 negative, 4/23 positive, $15 / 23$ no effect, $1 / 23$ BMI significant increase only for control group and 3/23 no data available). Conclusions. There is a need to prioritise interventions with study designs of high quality, theory, and a participatory approach, for optimal implementation and evaluation of obesity prevention interventions.
\end{abstract}

\section{Introduction}

The rise in obesity in the past several decades has been dramatic worldwide, particularly in the Western world. According to data from 2016, WHO reports that the Nordic countries and the Netherlands have similar rates for overweight and obesity (people with a BMI $\geq 25 \mathrm{~kg} / \mathrm{m}^{2}$ ) that vary within 4 percentage points; from Denmark with the lowest $55.4 \%$ to Iceland with the highest $59.1 \%$. These rates are lower than many Western countries (such as Canada, USA, Australia, New Zealand, UK, France, Spain, Greece, and the Middle East). Similar are the results for obesity (lowest for Denmark with $19.7 \%$ and highest for Norway with 23.1\%). These rates are also lower than many Western countries, as mentioned above (excluding France) [1]. However, these rates are still considered high and suitable initiatives are needed in order to reduce them.

Nordic countries and the Netherlands are highly regulated welfare states. They are also countries in geographical proximity with similarities in their societies such as economic and social policies. Therefore, these countries can apply similar initiatives and can be compared with each other. A regional focus allows for a more targeted analysis and provides results and conclusions that can benefit at the regional level $[2,3]$. In addition, these countries prioritise public health and have been progressive in implementing health promotion strategies, addressing the lifestyle determinants of obesity at a national level. These strategies have included the provision of national nutrition and physical activity (PA) guidelines and associated campaigns, positive changes to school curriculum, and, in Sweden and Finland, the provision of free school lunches and financial incentives for health promotion at the worksite. Nordic countries, in recent years, have also seen a general shift of responsibility for obesity prevention interventions to the local municipality level [2]. Therefore, they can provide valuable information about health promotion in relation to obesity, compared to other European countries or even serve as a model/example for the other countries.

Well planned, implemented, and evaluated setting-based interventions are paramount in measuring the success, 
future directions, and financial commitment of interventions for obesity prevention. Bottom-up approaches enable taking into account the needs of the intervention participants and the characteristics and resources of the context. This makes interventions more feasible to implement and more salient to the participants; these aspects increase the sustainability of desired outcomes. Research evidence supports the bottom-up approach since it can help overcome barriers of required change [4].

Multilevel approaches that involve the environment of the individual are highly significant for fighting the obesity epidemic, as environmental factors are often a root cause of obesity [5-7]. Integrated, multilevel approaches are needed instead of single level interventions targeting separate determinant levels [8]. These approaches involve intervention components that create a "healthier environment," such as school curricula and built environment changes, in addition to traditional approaches such as individual counselling and screening that have a limited impact. An example of the environmental approach in childhood obesity prevention could be changing the classroom interior, to allow physical activity in all lessons, instead of only during physical exercise lessons. Monitoring this practice showed clear decrease of obesity among the school children in Finland in the school setting-with results in obesity decrease [9].

The school setting is equally important both for children and their parents, especially as this setting is where children spend a large amount of their time during the day. Schools are places where children consume one or more meals per day. They are places where canteens, vending machines, and restaurants are often available which can negatively influence children's eating habits. In addition, children spend a lot of time sitting in school. Physical education, as well as the provision of available spaces for play and activities, can improve their PA levels. School-based interventions have provided evidence for effectiveness of childhood obesity prevention [10].

Similarly, the worksite setting is of high importance, due to the considerable amount of time most adults spend at work. There are also opportunities to improve the worksite with exercise facilities, such as access to gyms, and with improved access and availability of healthy food provided in restaurants, canteens, or as snacks that can encourage people towards healthier habits.

Community-based interventions are also very important because they can create a healthier environment for people to live in, through parks, policies on fast food, cycling and jogging tracks, awareness campaigns, and so on. Therefore, they can be very powerful for affecting diet and PA habits in a community [11].

A thorough review of community-based interventions, addressing obesity prevention in the Netherlands through an equity lens, reported that these interventions have impacted socioeconomic inequalities in health behaviour positively and negatively [3]. A recent review of lifestyle interventions implemented in European schools including five studies from Norway, Iceland, Sweden and the Netherlands revealed limited studies which reported a reduction in Body Mass Index (BMI) [12]. Moreover, results from a scoping review of
71 community-based interventions against childhood obesity in Europe revealed limited studies where BMI was measured as an outcome [13].

Furthermore, reviews of health promotion interventions implemented at the worksite, globally and in Nordic countries, have found that the majority of studies utilised the worksite as a convenient setting to implement interventions targeted at individual behaviour change, rather than use a setting-based, multilevel approach including changes to the worksite environment [14-16]. To the knowledge of the authors, no review has been identified which has given an overview of all setting-based obesity prevention interventions, implemented in Nordic countries and the Netherlands.

Different components that define the quality of a study such as representativeness, randomisation process, comparability of chosen intervention and control groups, attrition rate, and spillover effect/attributability to intervention also need to be considered. The quality of a study affects highly the outcome, and a low-quality study might obscure the impact of the intervention otherwise evidenced. Another important element in evaluating the quality of interventions and an integral part of designing and planning complex interventions is the use of theory. This has also been acknowledged by the British Medical Research Council and forms part of its guidance [17].

The aim of this review was to identify, synthesise, and evaluate the quality of interventions including environmental components based in the in settings from Nordic countries and the Netherlands, aimed at preventing obesity where BMI was measured and reported as an outcome.

\section{Methods}

The review of the literature was completed systematically, guided by the PRISMA (Preferred Reporting Items for Systematic Reviews and Meta-analyses) statement [18], with guidance for the search strategy from a previous review of whole of community interventions [11]. The eligibility criteria for the studies selected was defined using PICO (Participants, Intervention, Comparison, Outcome).

2.1. Types of Participants. Interventions targeted all age groups, living in either the Netherlands or the Nordic countries: Denmark, Finland, Iceland, Norway, and Sweden, regardless of socioeconomic status (SES). The Nordic countries were included in the review based on geographical and cultural similarities. The Netherlands were included due to the similarities of their historical welfare model to that of the Nordic countries in general [19]. Studies selected included participants that were otherwise healthy, for example, not obese or with a preexisting condition, for example, hypertension.

2.2. Types of Interventions. We chose interventions in the community, school, and worksite setting with at least one environmental component. The community is considered a setting as much as the worksite and school [20]. Planned community-based interventions targeting the weight status of a population, characterised along geographical boundaries, 
such as cities, villages, or regions, are commonly defined as "whole of community" interventions [21]. An environmental component was defined as any effort in the setting that did not include individual-based strategies such as counselling for individuals, web-based computer-tailored feedback, or individual counselling. Such components were, for example, school curriculum changes, infrastructure and built environment, policies, restaurants, and so on. Since all studies had at least one environmental component, they were all socioecological models [22].

No restrictions were made to length of follow-up. English language studies published in the literature up to and including April 2016 were included in the review. Hospitalbased clinical interventions or those primarily based in the primary care setting were excluded. Furthermore, worksitebased interventions were excluded if the target group was deemed too specialised and not representative of the general population of employees, for example, one professional group only. If there was more than one article referring to different follow-up points, the longest follow-up was chosen as the included article.

2.3. Types of Studies. All intervention study designs other than purely qualitative were included.

2.4. Outcome Measures. Interventions where the outcome was obesity or chronic disease prevention and where BMI was measured and reported as either a primary or secondary outcome were included. Studies that measured only behavioural outcomes including dietary or PA levels were excluded.

2.5. Search Strategy. A thorough search of the databases Medline and Embase through the Ovid search strategy was completed for articles published until April 2016 (Table 1). Additional sources included articles sourced from reference lists of review articles, identified through the original Ovid database search strategy, and from a search of databases: health evidence reviews and the cochrane database. Other sources by snowballing included articles identified from screening references of full-text articles. One researcher essentially performed the search and screening. After duplicates were removed, records were screened by title and abstract by the selection criteria, before full-text articles were identified. Reasons were provided for why articles were excluded by full-text. Full-text articles were reviewed by all authors.

2.6. Extracted Information. Studies meeting the inclusion criteria by full-text were classified by setting and country. Data were extracted independently by two researchers. A descriptive analysis of the studies involved extracting information including study design, participants, gender as a percentage of females, mean age (SD), total follow-up, measure of SES (education), and if a theoretical base (data not shown) was used for the intervention design and implementation. Further assessment of the outcomes of each study was reviewed with information extracted including the outcomes measured, description of the study population units, response rate and loss to follow-up, randomisation used, selection process for setting or community of choice, summary of intervention implemented, and lastly the outcome related to BMI. Where information was insufficient regarding baseline data or intervention design for a particular article, additional reference articles were sourced from respective reference lists or via a search in Pubmed by study name. Lastly, some additional estimated calculations were made by the authors for the response rate, lost to follow-up, and gender, based on the information available from the articles.

2.7. Quality Assessment of Studies. An analysis of the methodological quality of the studies was then completed using a quality assessment tool [23], previously used by the authors of a review of lifestyle interventions in the Netherlands $[3,23]$. The quality assessment was performed independently by two researchers. Representativeness was considered as a response rate of $60 \%$ or more in samples randomly recruited from the study population, or that the study showed otherwise to be representative of the population [3]. In the case of the whole of community interventions, we considered the participants within the community (random selection) as units to determine representativeness. For the other setting-based interventions, we considered the schools or worksites as units to determine representativeness (not the children or students). We also considered the choice of setting/community (e.g., convenience, volunteering, and participation in existing programs) in order to judge whether a sample was representative or not.

Finally, comparability was difficult to determine, especially if some but not all baseline characteristics were similar. Available data were assessed when a study included BMI in their baseline description and were deemed noncomparable if there were differences in BMI, even if there were no differences in other characteristics. In addition, we considered the baseline characteristics comparable, if the intervention and control group were matched or selected based on similar characteristics, such as SES.

2.8. Data Synthesis. Data is presented by setting in the following order: whole of community, worksite, and school. Data were not pooled or regrouped based on specific characteristics but are presented and discussed as separate settings. Pooling or regrouping of the data was not possible due to the heterogeneity of the studies.

\section{Results}

The literature screening process is presented in Figure 1. The major search revealed 2873 articles, and additional sources revealed 53 more articles. After removal of duplicates, 1575 were available for screening. Screening by title and abstract led to 84 full-articles; of those, 33 were finally included for analysis [24-56]. 
TABLE 1: Search strategy, medline and EMBASE via ovid.

(1) obesity.mp.

(2) childhood obesity.mp.

(3) overweight.mp.

(4) exp Obesity/pc [prevention and control]

(5) exp Cardiovascular disease/pc [Prevention \& Control]

(6) (body mass index or BMI).mp.

(7) (Denmark or Danish or Dane\$).mp.

(8) (Sweden or Swedish or Swede\$).mp.

(9) (Norway or Norwegian\$).mp.

(10) (Finland or Finnish or Finn\$).mp.

(11) (Iceland or Icelandic or Icelander\$).mp.

(12) (Netherlands or Dutch).mp.

(13) (Nordic or Scandinavia\$).mp.

(14) communit\$.mp.

(15) (population based or population-based).mp.

(16) (community based or community-based)mp.

(17) (whole of community or whole-of community).mp.

(18) (community wide or community-wide).mp.

(19) national.mp.

(20) state.mp.

(21) regio\$.mp.

(22) local.mp.

(23) municip\$.mp.

(24) district.mp.

(25) town $\$ . m p$.

(26) village\$.mp.

(27) borough.mp.

(28) precinct.mp.

(29) (county or counties).mp.

(30) area.mp.

(31) province.mp.

(32) shire.mp.

(33) urban.mp.

(34) rural.mp.

(35) (city or cities).mp.

(37) (school based or school-based).mp.

(38) (secondary school or secondary-school).mp.

(39) (elementary school or elementary-school or primary school or primary-school).mp.

(40) (pre-school or preschool).mp.

(41) pupil\$.mp.

(42) student\$.mp.

(43) kindergarten\$.mp.

(44) childcare.mp.

(45) nurser\$.mp.

(46) daycare.mp.

(47) worksite\$.mp.

(48) worksite\$.mp.

(49) employee\$.mp.

(50) worker\$.mp.

(52) intervention study.mp.

(53) prevention.mp.

(54) primary prevention.mp.

(55) program $\$ . m p$.

(56) (community intervention\$ or community-intervention\$).mp.

(57) (community program $\$$ or community-program $\$$ ).mp.

(58) (health promotion or promotion).mp.

(59) (lifestyle intervention or life-style intervention).mp.

(60) exercise intervention.mp.

(61) (physical activity or physical actvity intervention).mp.

(62) (diet\$ intervention or healthy eating intervention).mp.

(63) environment\$ intervention.mp.

(64) policy.mp.
TABle 1: Continued.

(65) policy implementation.mp.

(66) project.mp.

(67) study.ti.

(68) (randomi\#ed control stud\$ or randomi\#ed control trial or

RCT).mp.

(69) cohort stud\$.mp.

(70) longitudinal.mp.

(71) prospective.mp.

(72) case control stud\$.mp.

(73) case series.mp.

(74) (cluster-randomi\#ed or cluster randomi\#ed or randomi\#ed).mp.

(75) quasi-experimental design.mp.

(76) interrupted time series.mp.

(77) pilot study.mp.

(78) program\$ evaluation.mp.

(79) effectiveness.mp.

(80) evaluation.mp.

(81) (follow up or follow-up).mp.

(82) 1 or 2 or 3 or 4 or 5 or 6

(83) 7 or 8 or 9 or 10 or 11 or 12 or 13

(84) 14 or 15 or 16 or 17 or 18 or 19 or 20 or 21 or 22 or 23 or 24 or 25 or 26 or 27 or 28 or 29 or 30 or 31 or 32 or 33 or 34 or 35 or 36 or 37 or 38 or 39 or 40 or 41 or 42 or 43 or 44 or 45 or 46 or 47 or 48 or 49 or 50 (85) 51 or 52 or 53 or 54 or 55 or 56 or 57 or 58 or 59 or 60 or 62 or 64 or 65 or 66

(86) 67 or 68 or 69 or 70 or 71 or 72 or 73 or 74 or 75 or 76 or 77 or 78 or 79 or 80 or 81

(87) 82 and 83 and 84 and 85 and 86

(88) Limit to English

Table 2 shows the descriptive characteristics and assessment of all three types of setting-based interventions, with Table 3 providing a summary of key characteristics of these setting-based interventions. Out of the total number of studies, seven were whole of community interventions $[37,39,42,44,45,52,56]$, three were worksite-based interventions $[34,36,43]$, and 23 were school-based interventions [24-33, 35, 38, 40, 41, 46-51, 53-55].

Weight prevention was a secondary outcome in five out of the 33 studies: changes in dietary habits [24], muscle development [55], health behaviour [28, 29], and increase in PA indicators [32]. These studies were all school-based interventions. Where required, some additional information was extracted, regarding theoretical constructs from additional articles related to the original studies [57-64] (data are not shown).

3.1. Whole of Community Interventions. Among the whole of community interventions, two were pre-post studies without a control group [37, 44], and there was no cluster randomised design in any of them. All other studies were quasiexperimental $[39,42,45,52,56]$. The percentage of females ranged from $46.0 \%$ to $57.2 \%$. There was no information for either education level or SES of the participants in $2[37,44]$ of the 7 interventions. BMI change for adults was measured in all studies. The total time of followup varied from three to eight years, and four interventions included a cohort (same individuals followed) and crosssectional samples [37, 42, 44, 56]. 


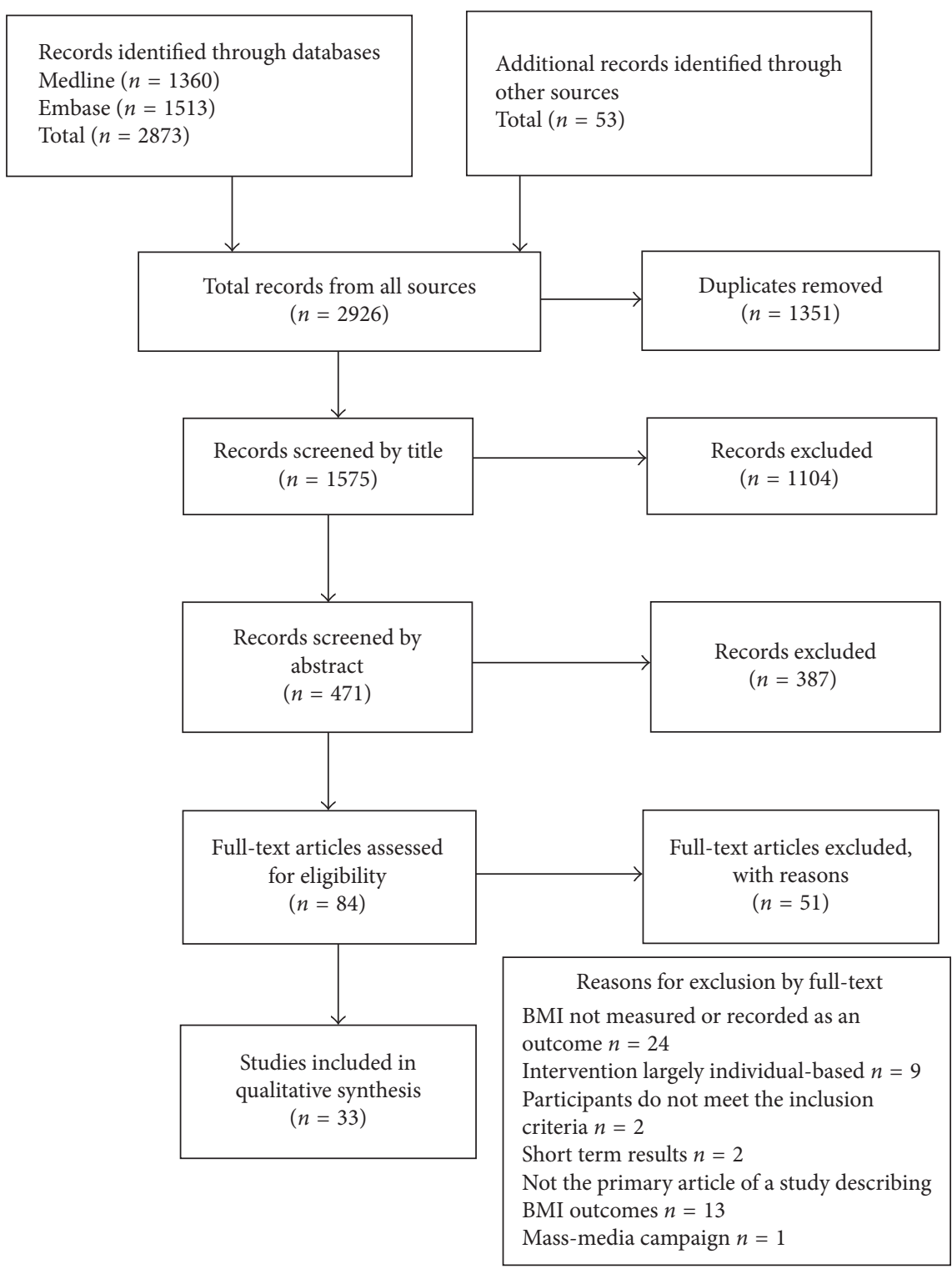

FIgURE 1: Study identification, screening, and eligibility, guided by PRISMA.

All whole of community interventions focused on risk factors for cardiovascular disease (CVD) and involved individual and environmental components in the interventions. Five studies were multicomponent studies (three components and above) $[37,39,45,52,56]$. Six studies were interested in diet, PA, and other risk factors [37, 42, 44, 45, 52, 56]. One study was interested in PA only [39]. Two interventions had components related to worksites $[39,45]$ and one intervention to schools and worksites [37] even though BMI changes for children were not measured in this study. Environmental components such as awareness campaigns were available in all seven studies [37, 39, 42, 44, 45, 52, 56], organised activities at little or no cost in six studies [37, 39, 42, 45, 52, 56], food stores in four $[37,44,52,56]$, infrastructure in two $[39,45]$, and policy in two (smoking) $[45,52]$. One study focused additionally on capacity building (at least as reported strategy) [37]. Only one [39, 59] of the seven whole of community interventions was explicitly theory-based and used a multilevel approach, and only one [45] mentioned a theory (data not shown).

Changes in BMI for the interventions are presented in Table 2 in a variety of ways, depending on the type of followup (wave of cross-sectional samples or cohort). Out of the seven whole of community interventions, two showed a significantly lower increase in $\mathrm{BMI}$ in the intervention (I) group compared to the control (C) group [39, 52]. One study showed a significantly higher increase in $\mathrm{BMI}$ in the I group compared to the C group [45], and another showed an increase in BMI in a before-after study (comparisons among cross-sectional samples) [44]. Three studies showed no difference (one before-after study with comparisons among cross-sectional samples [37], one with cross-sectional samples and a cohort [56], and one cohort [42]). For the one cohort in this category [42], the differences for I and C groups were not tested. In this category, for the study that included cross-sectional samples and a cohort [56], there 


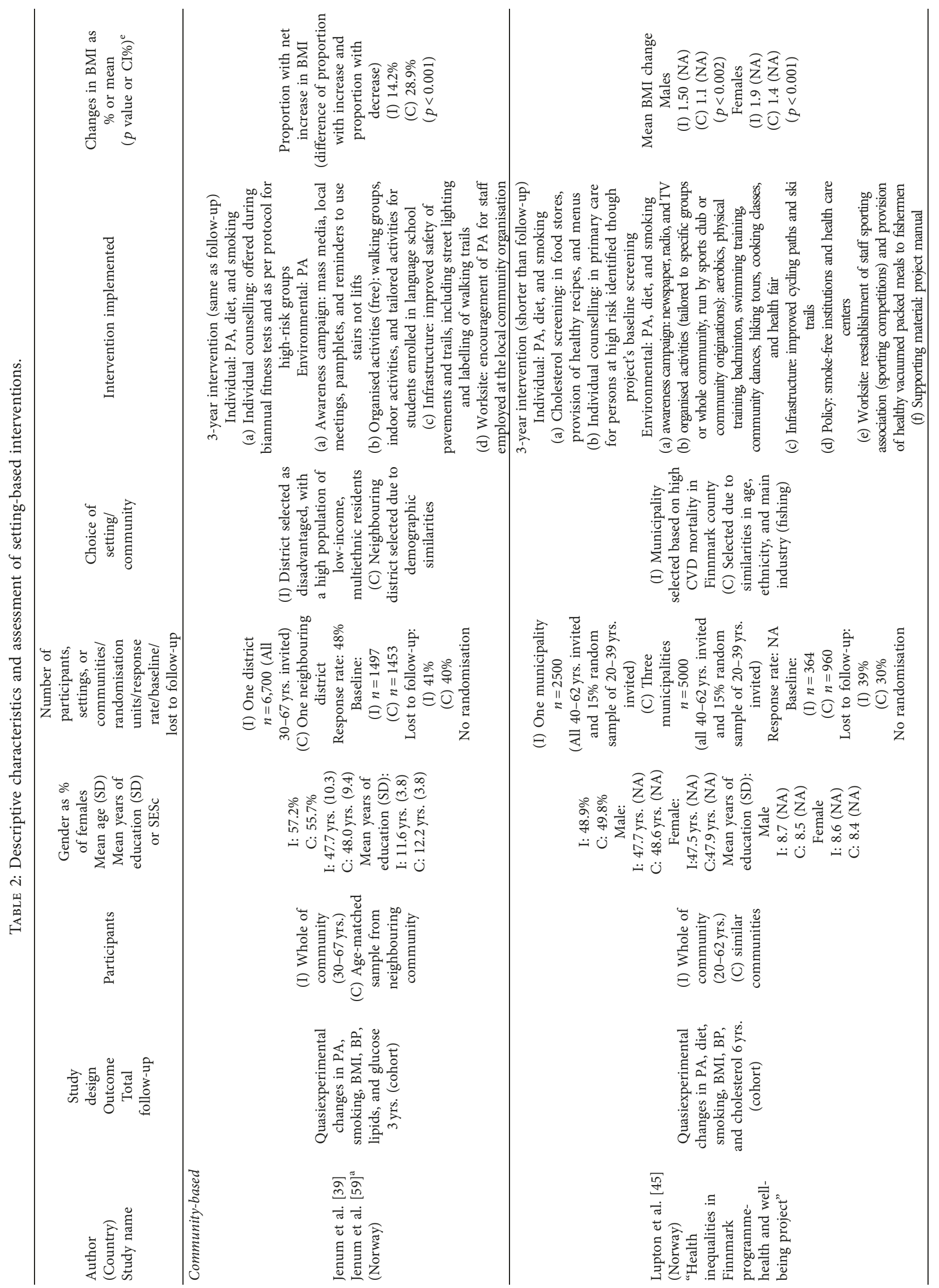




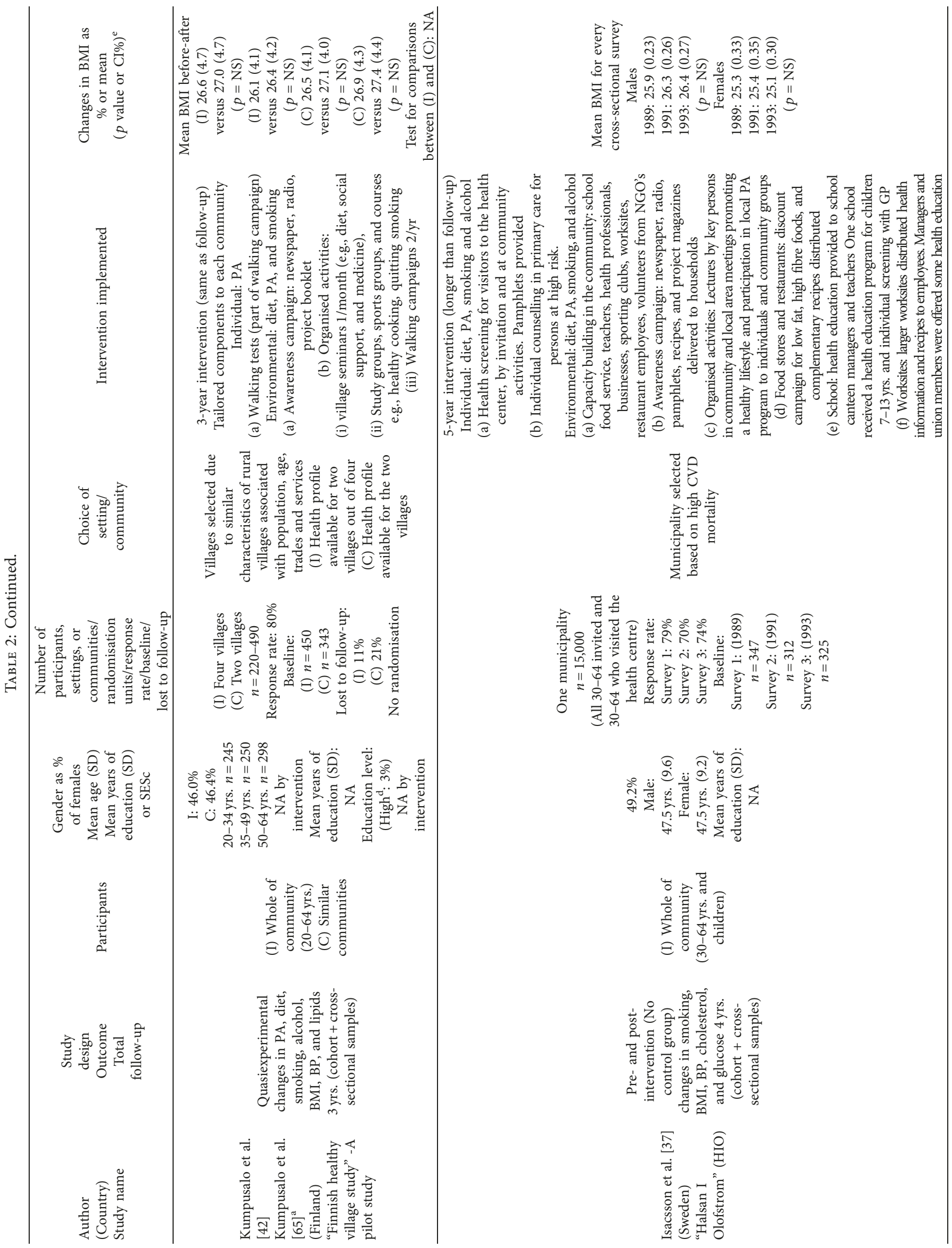




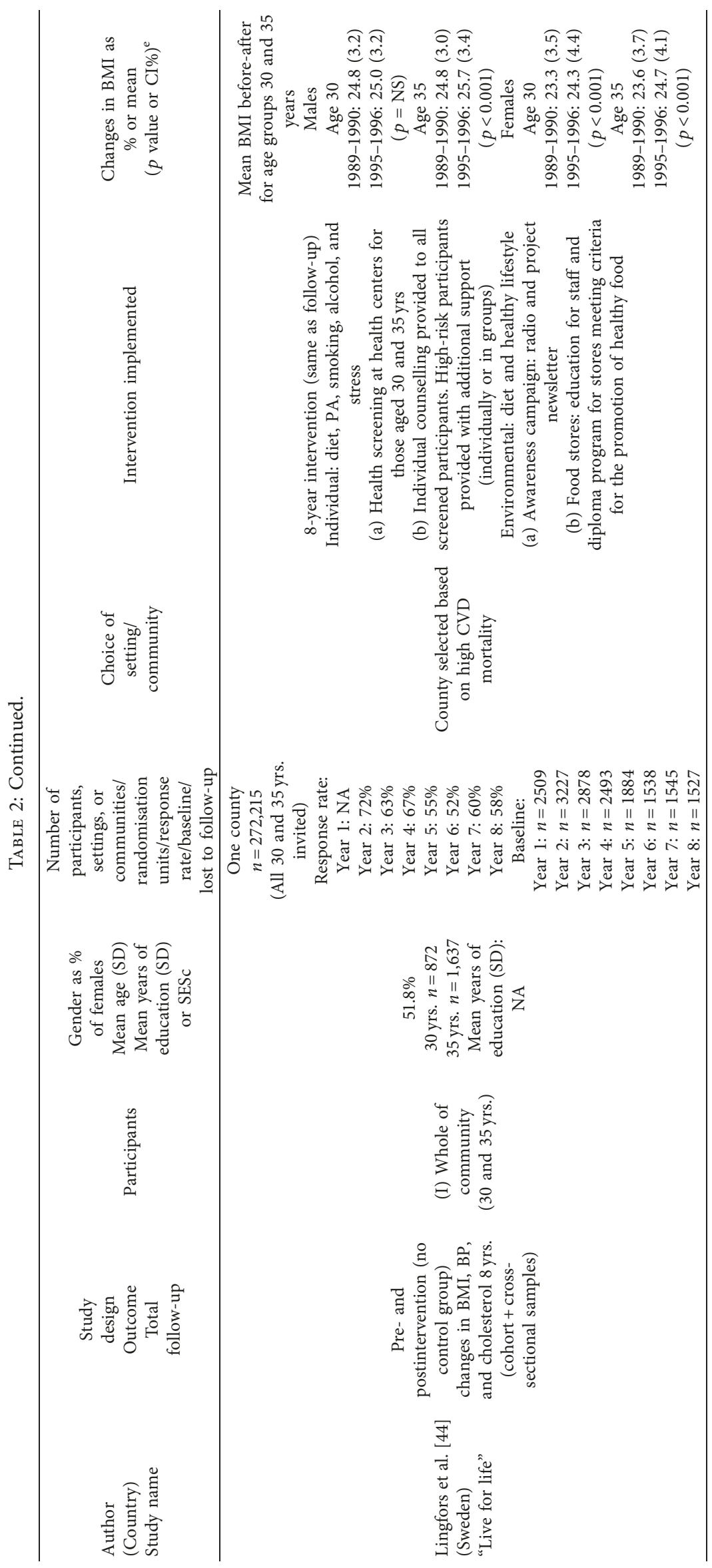




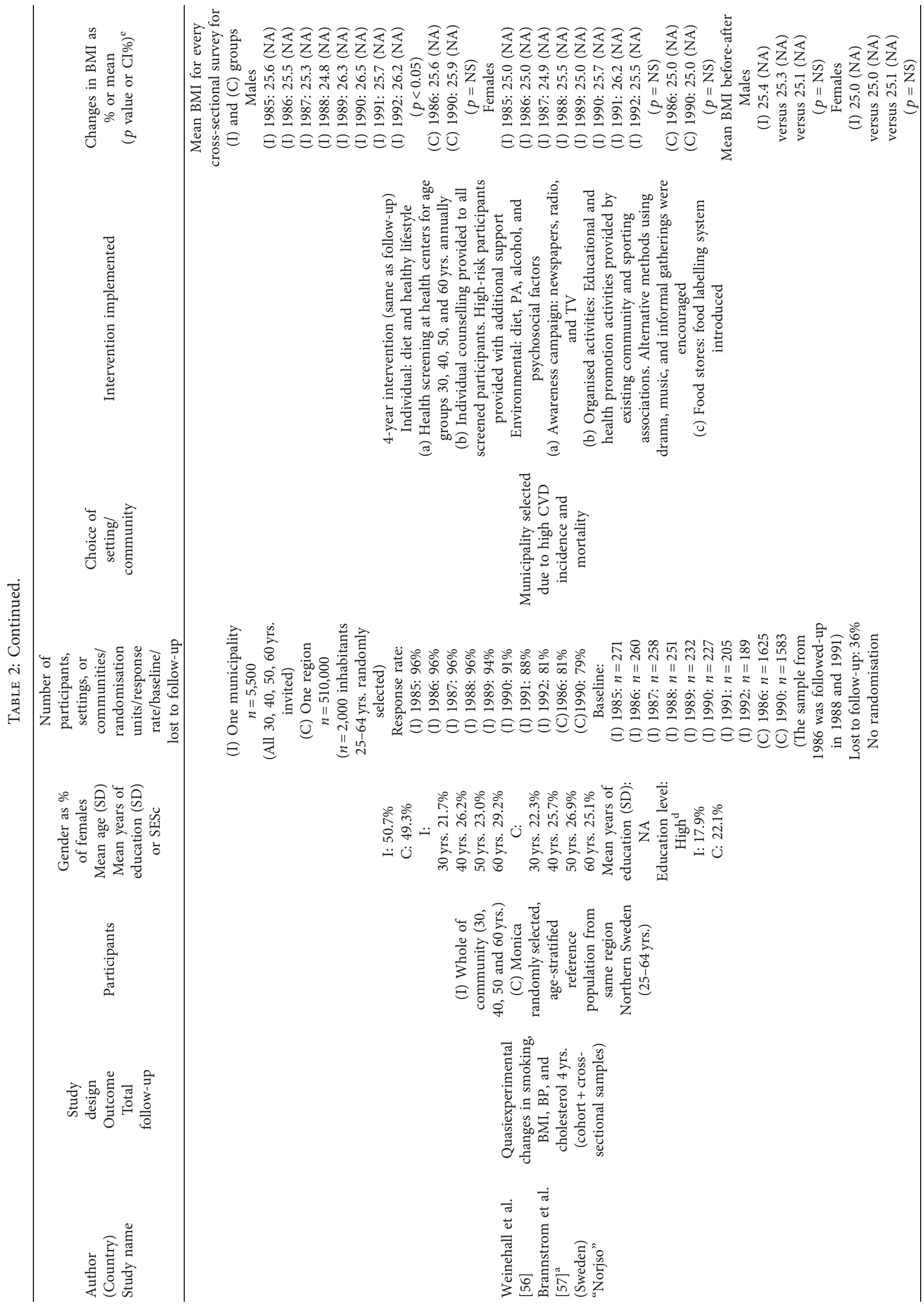




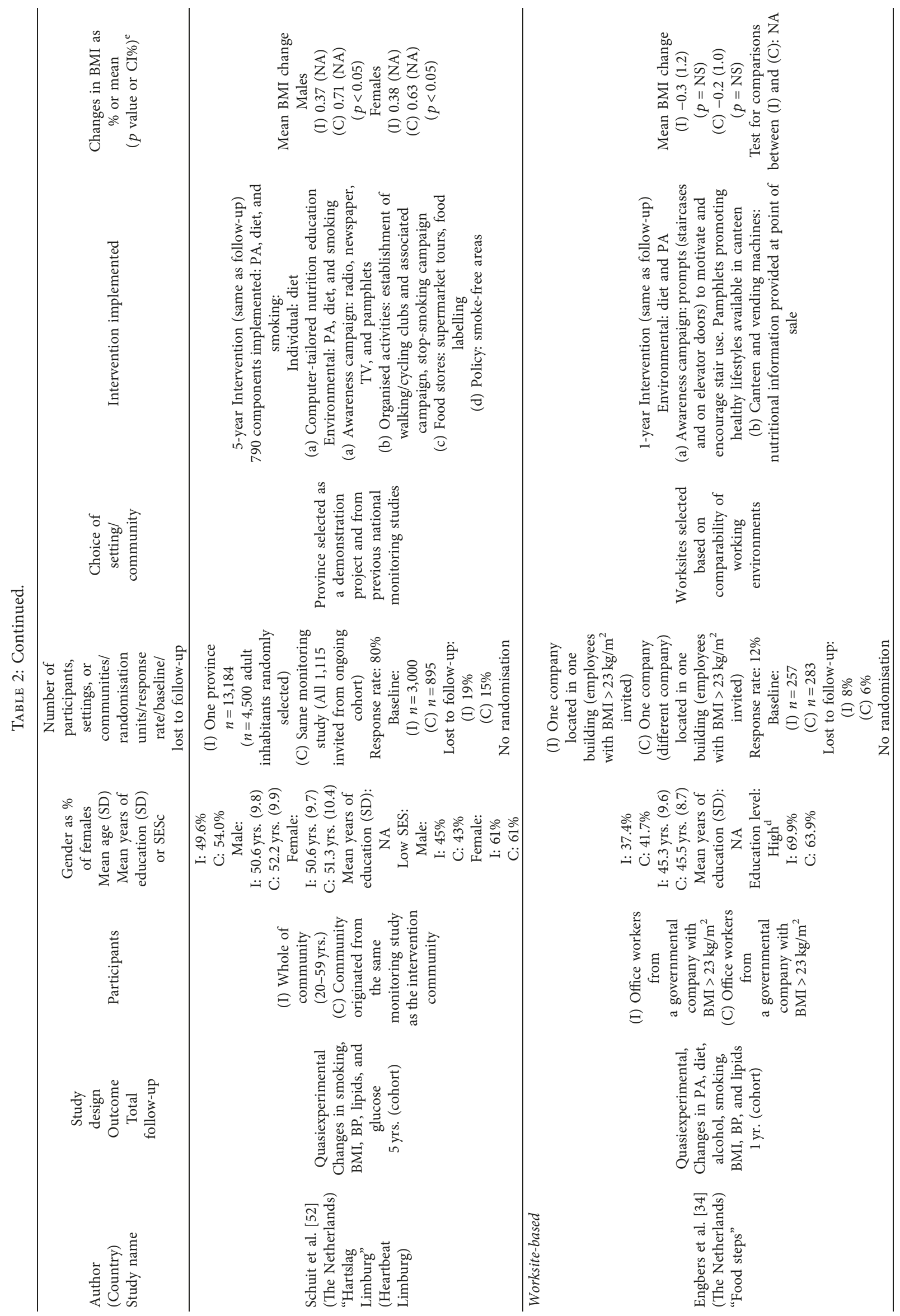




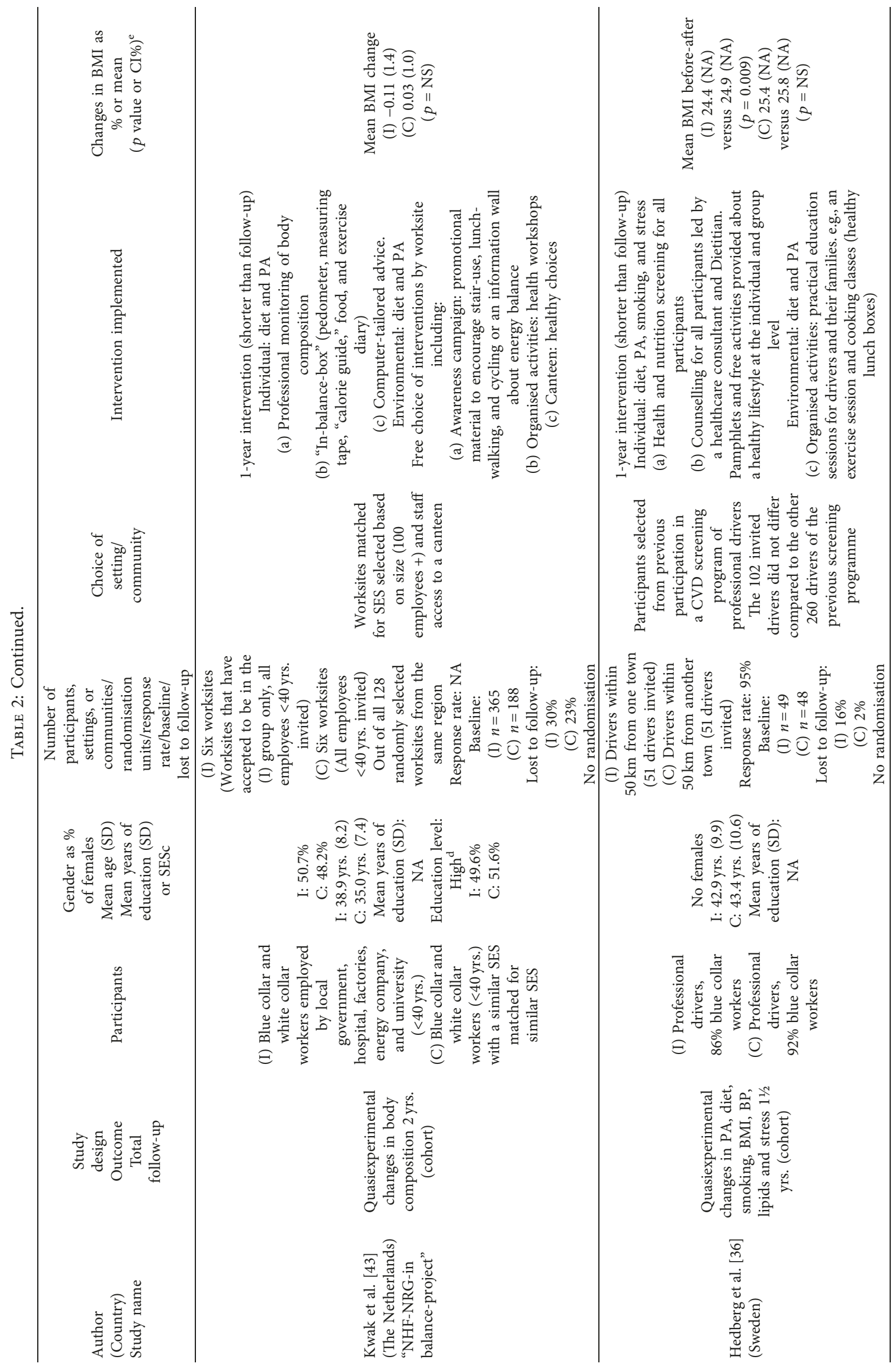




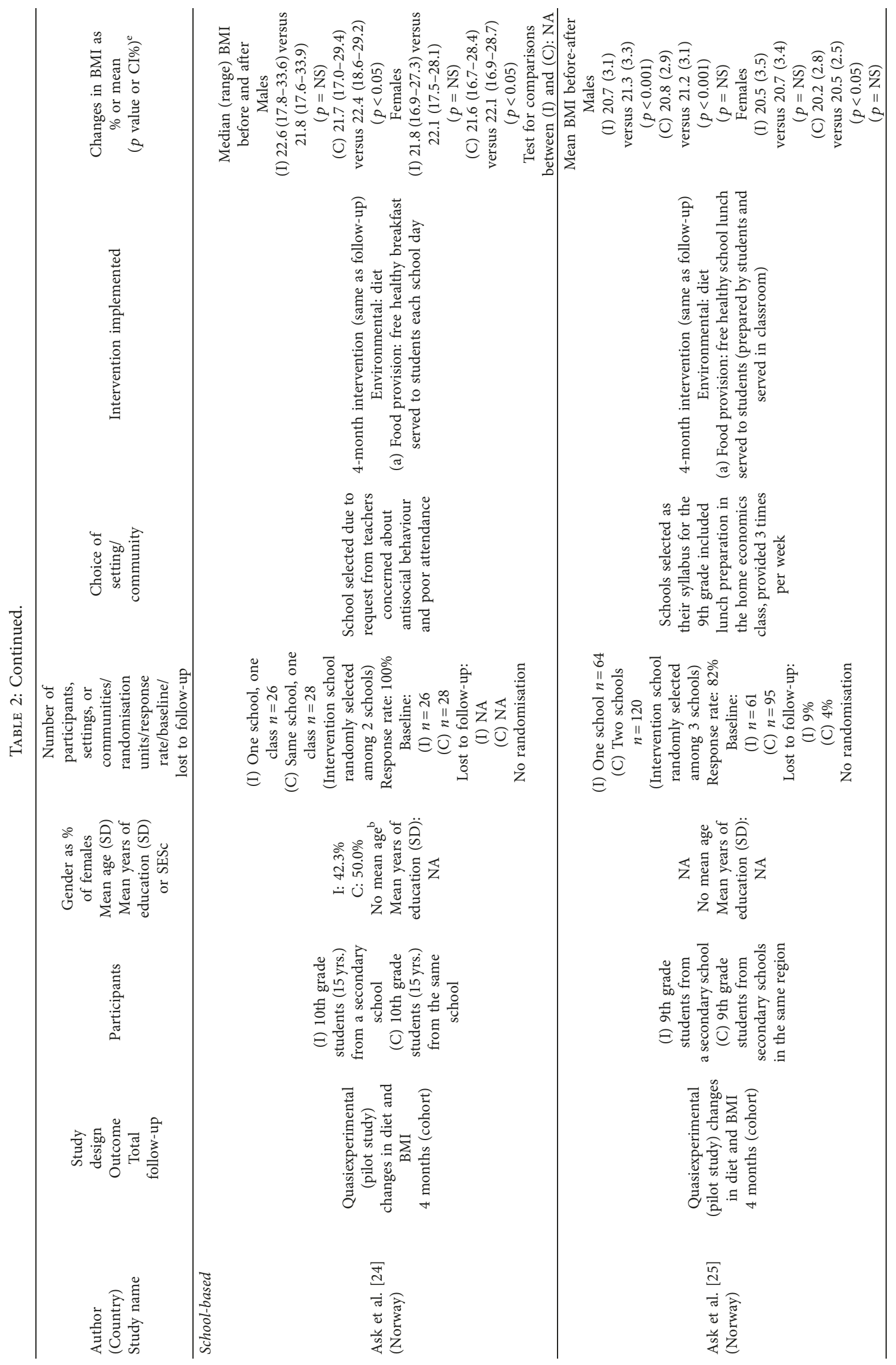



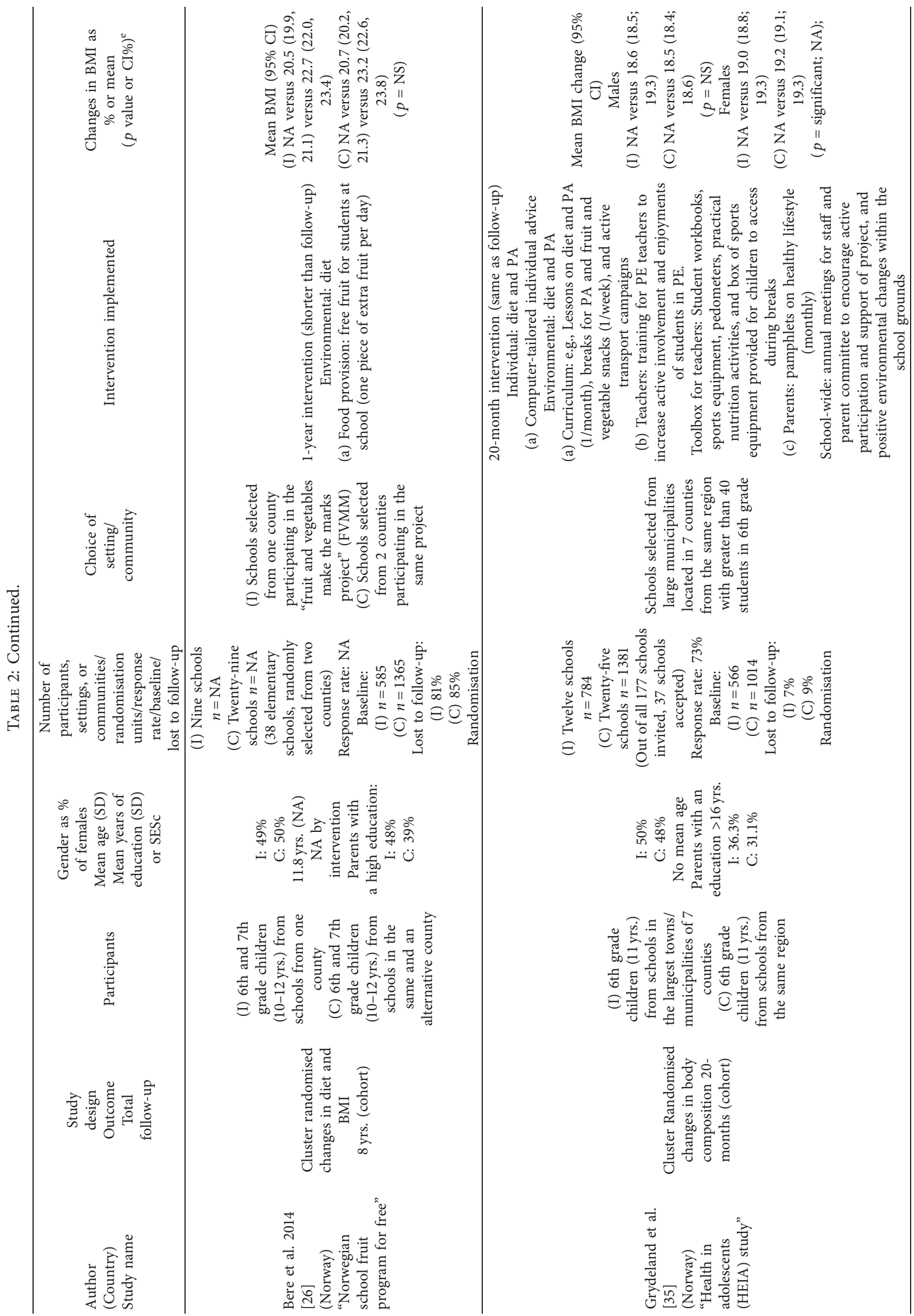


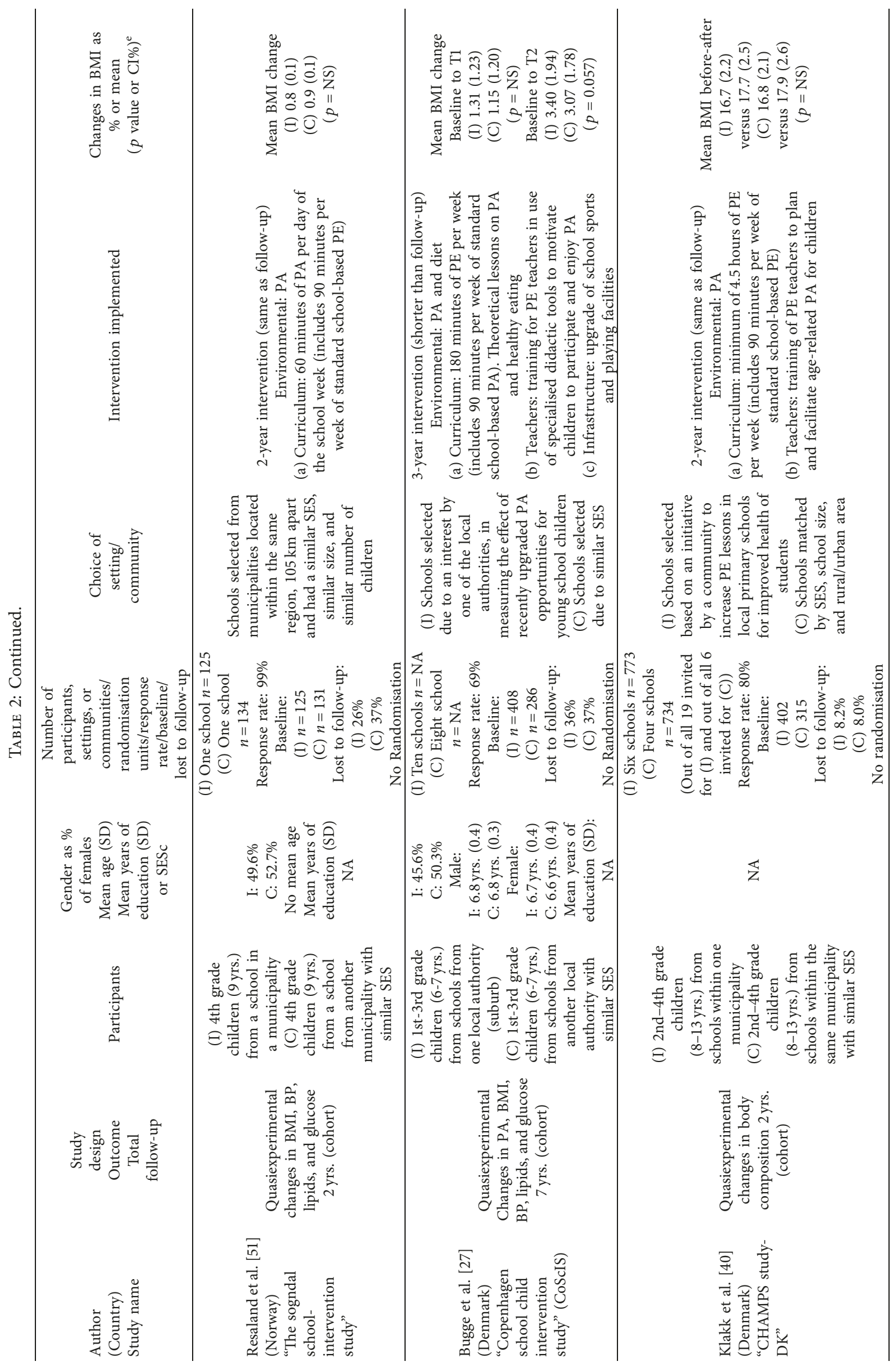




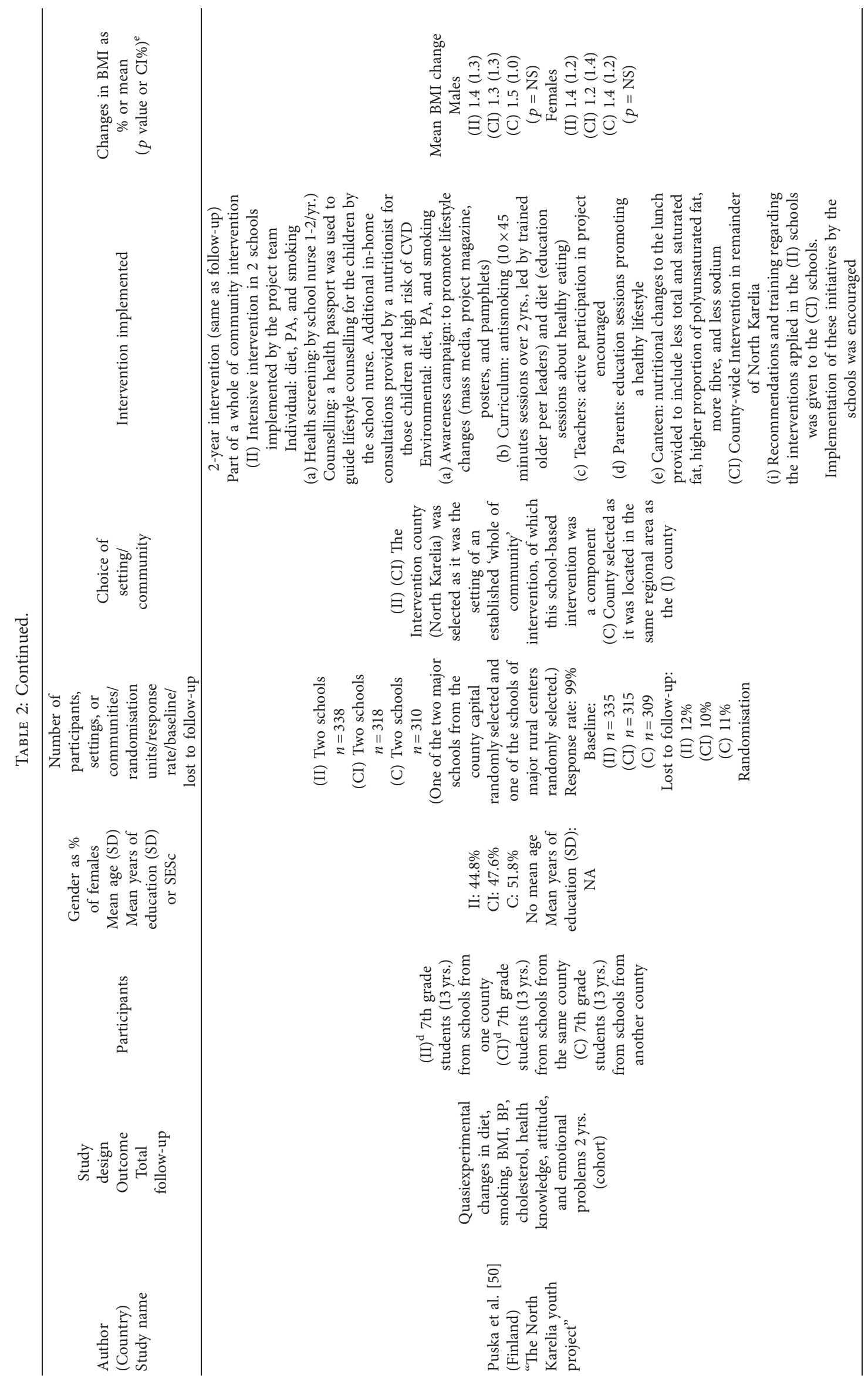




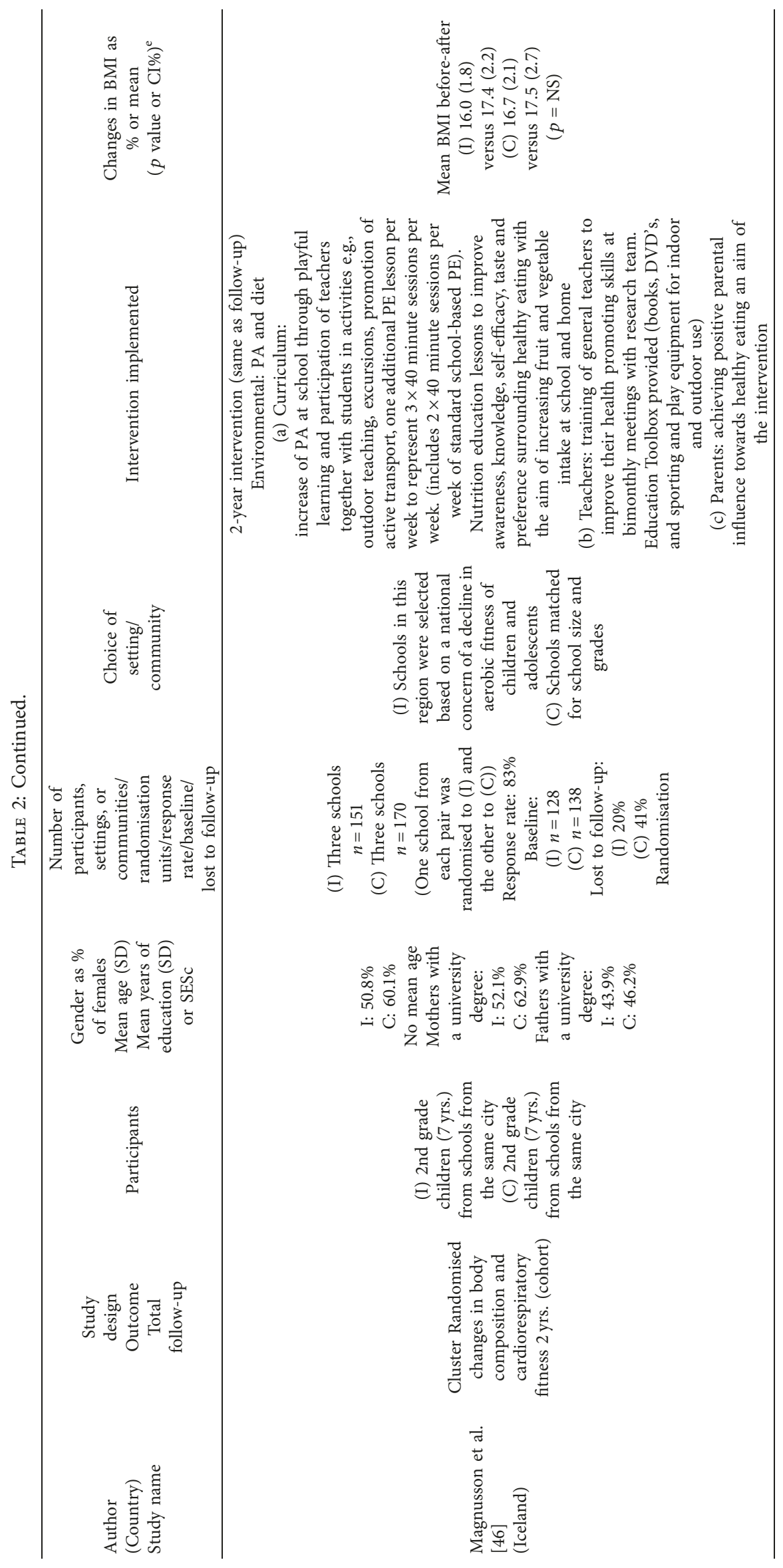




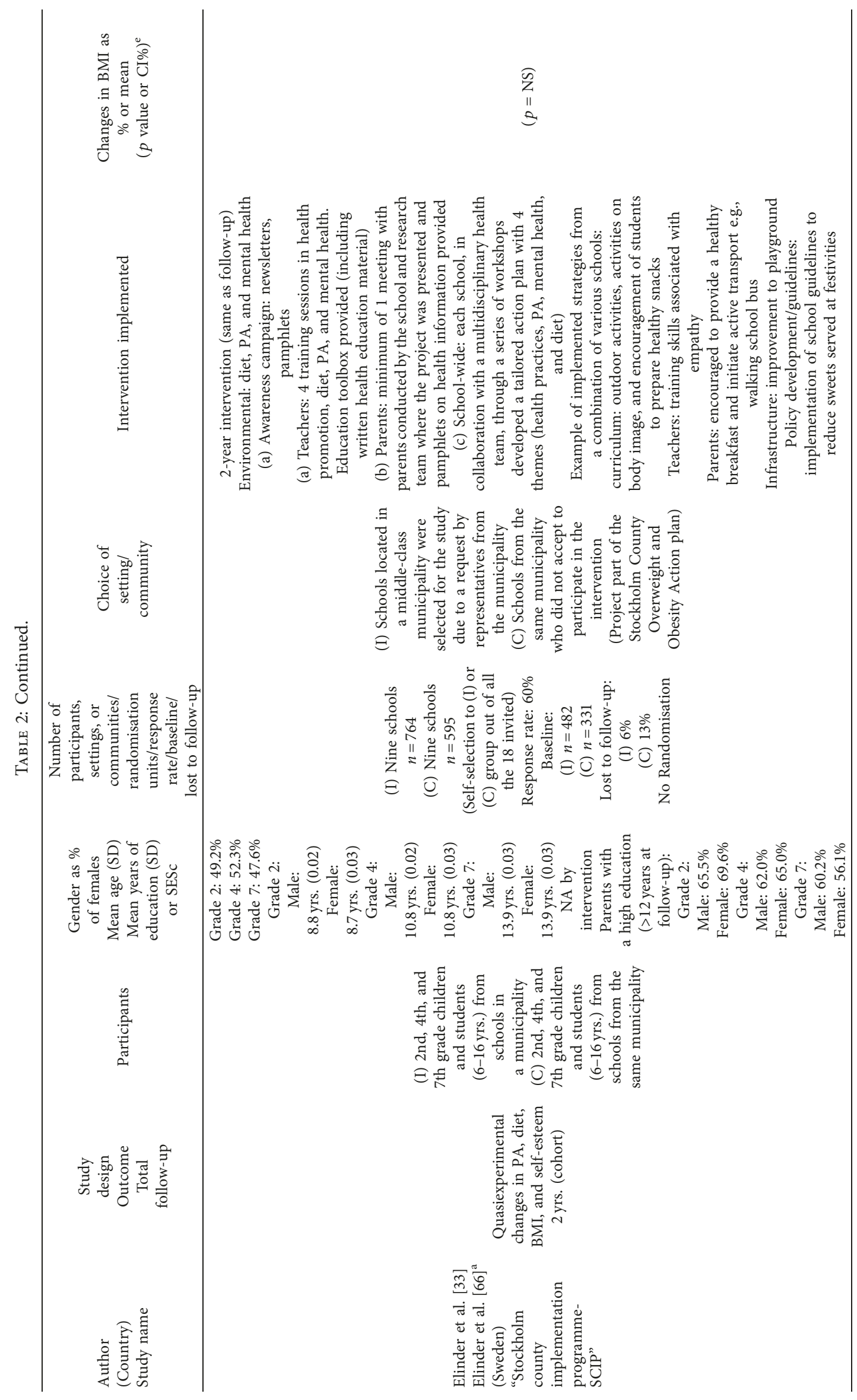




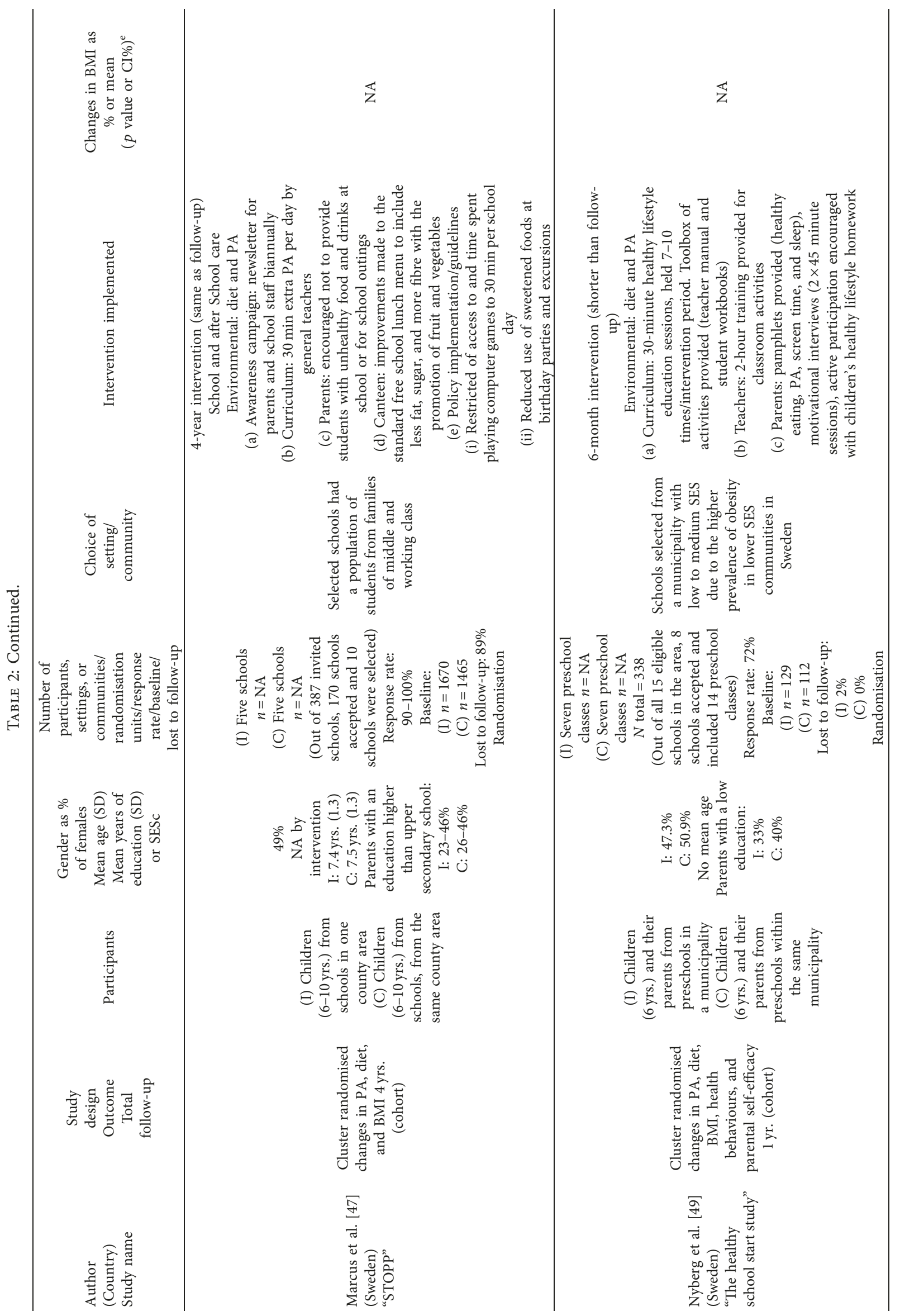




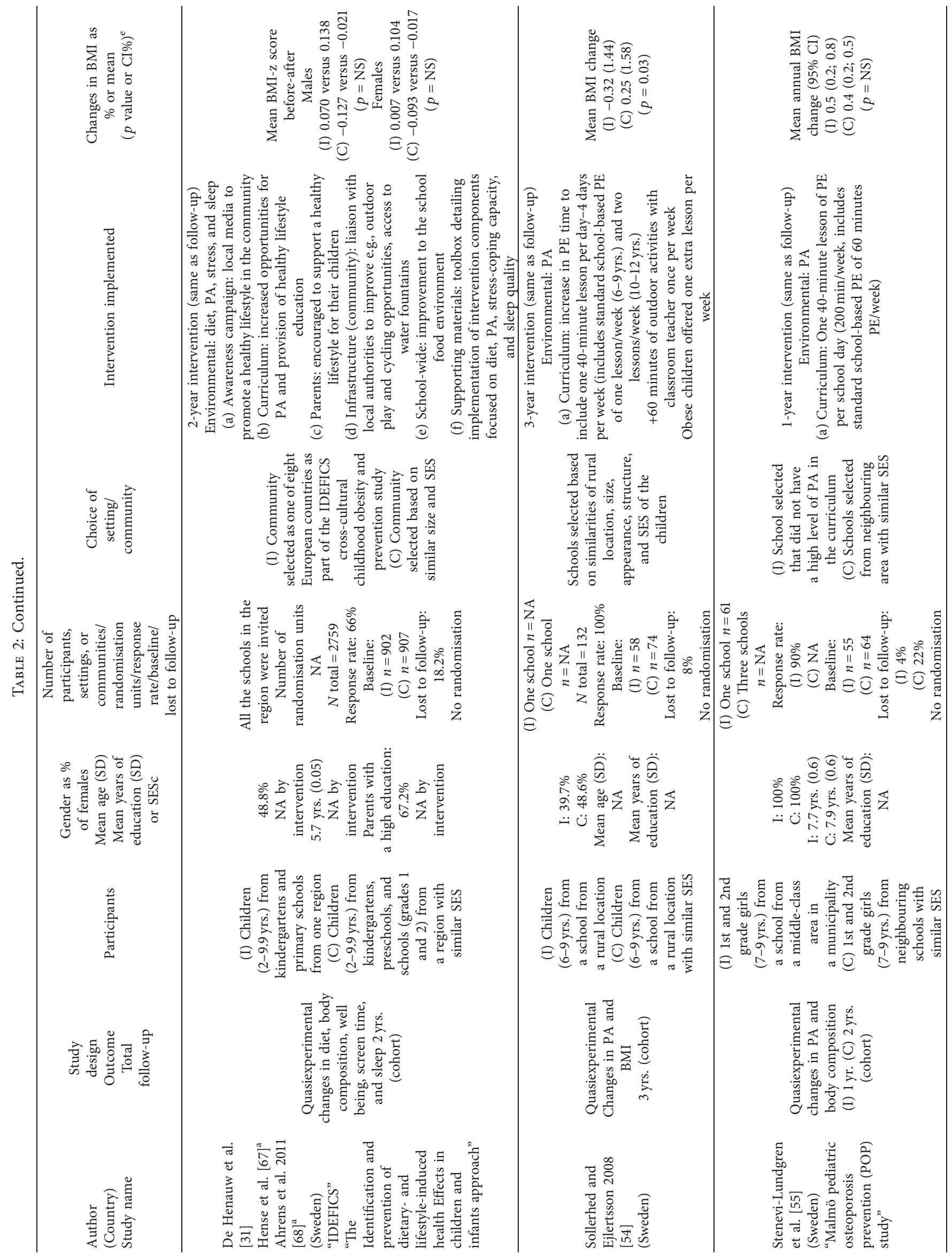




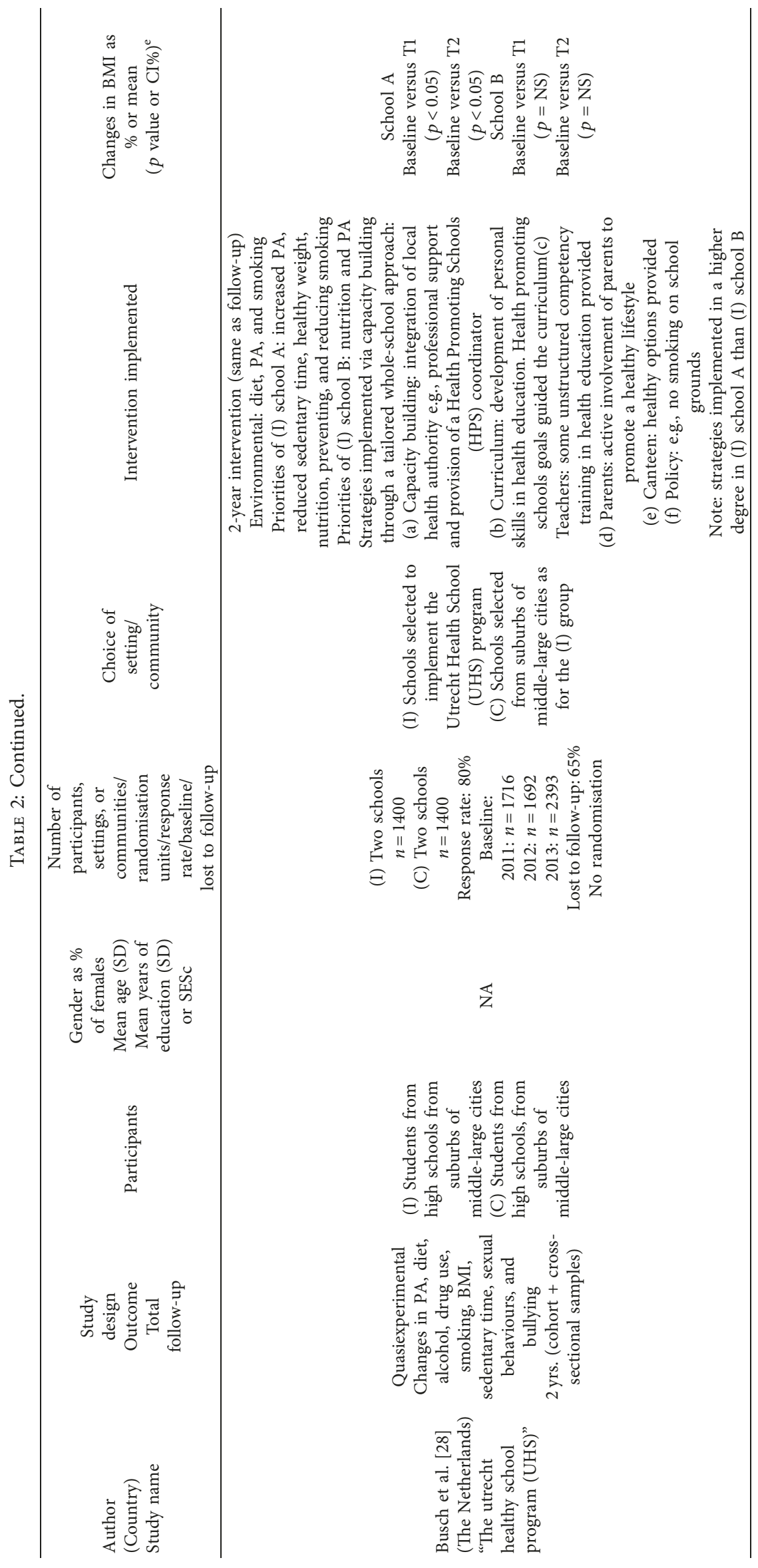




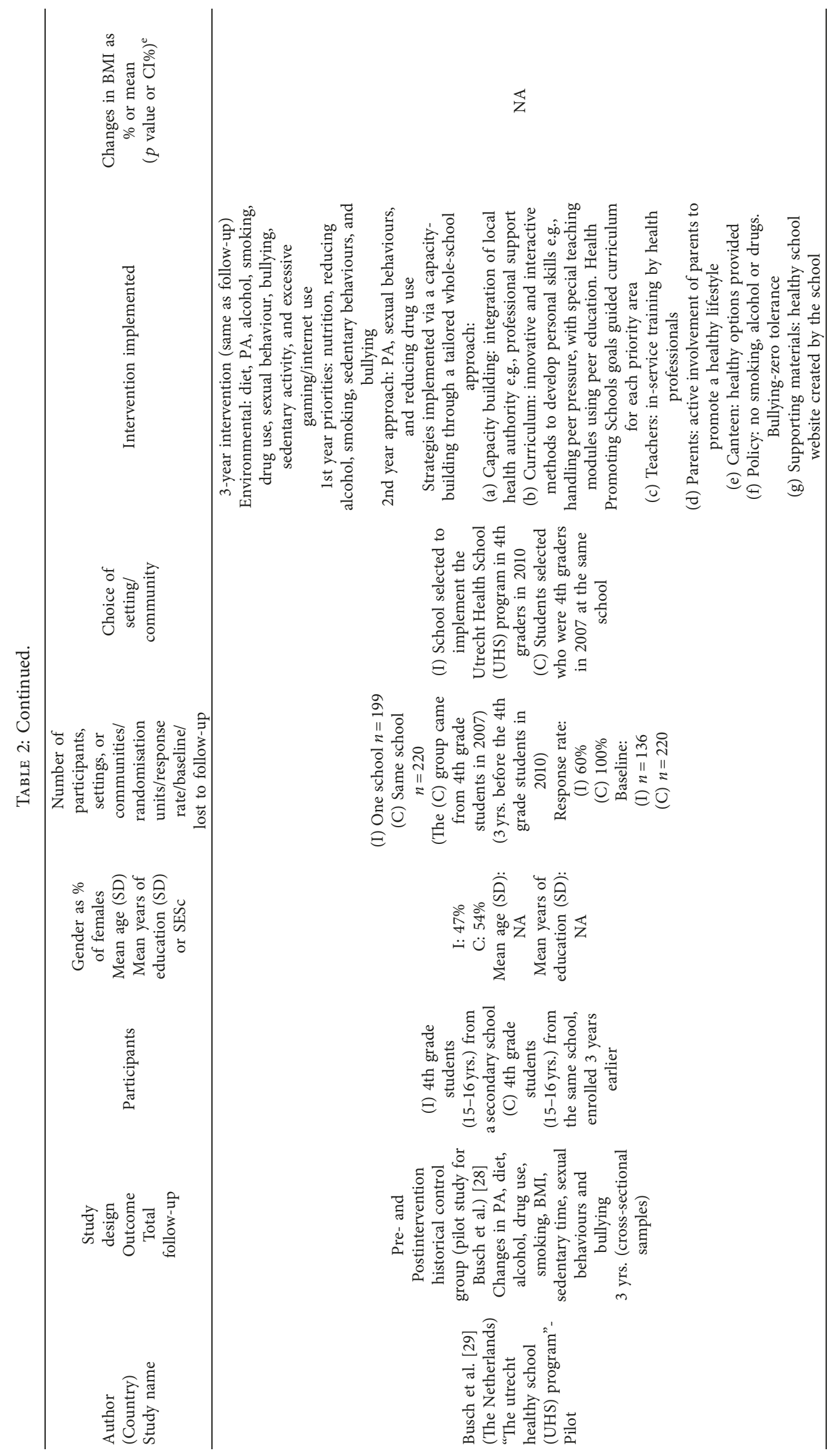




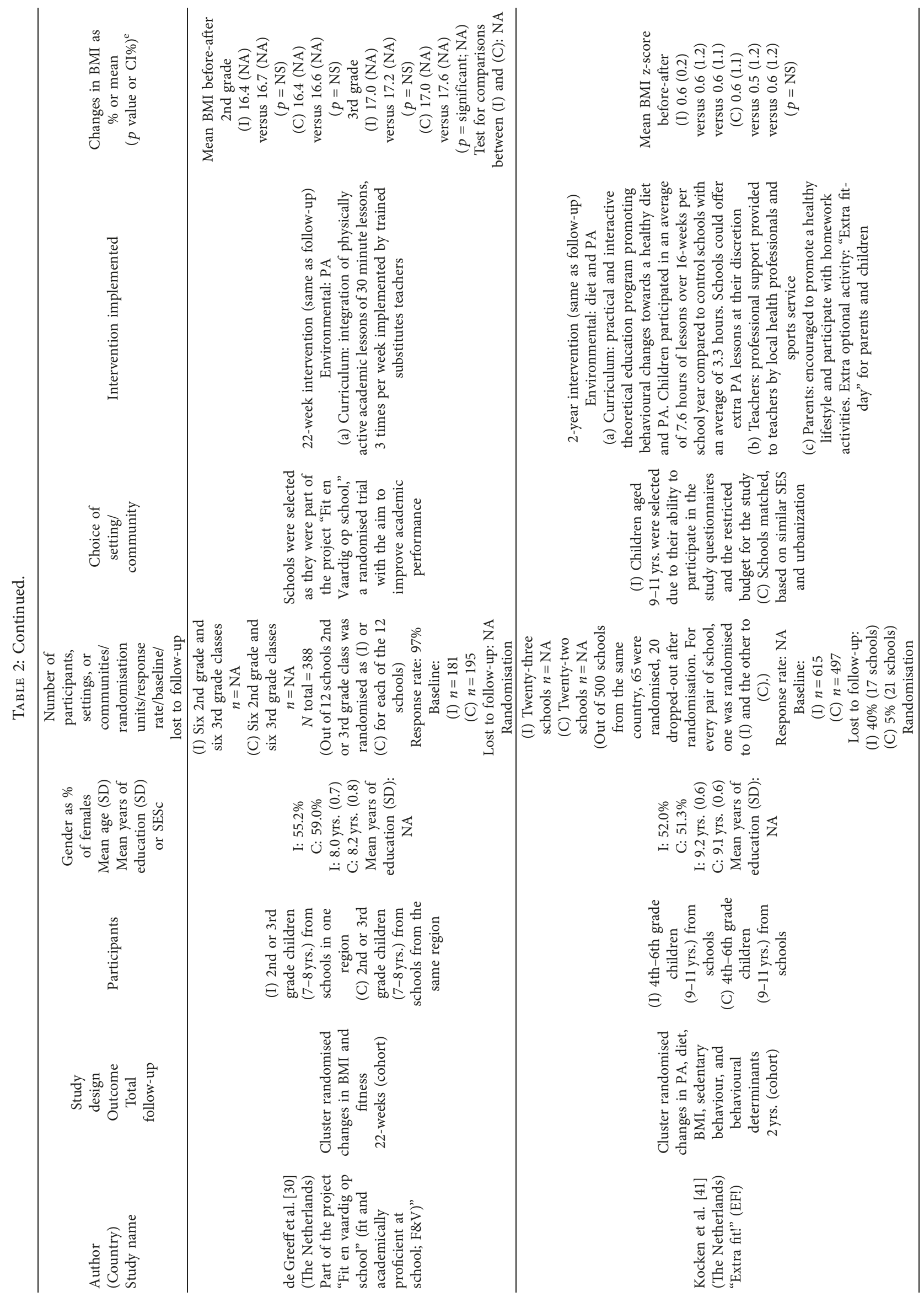




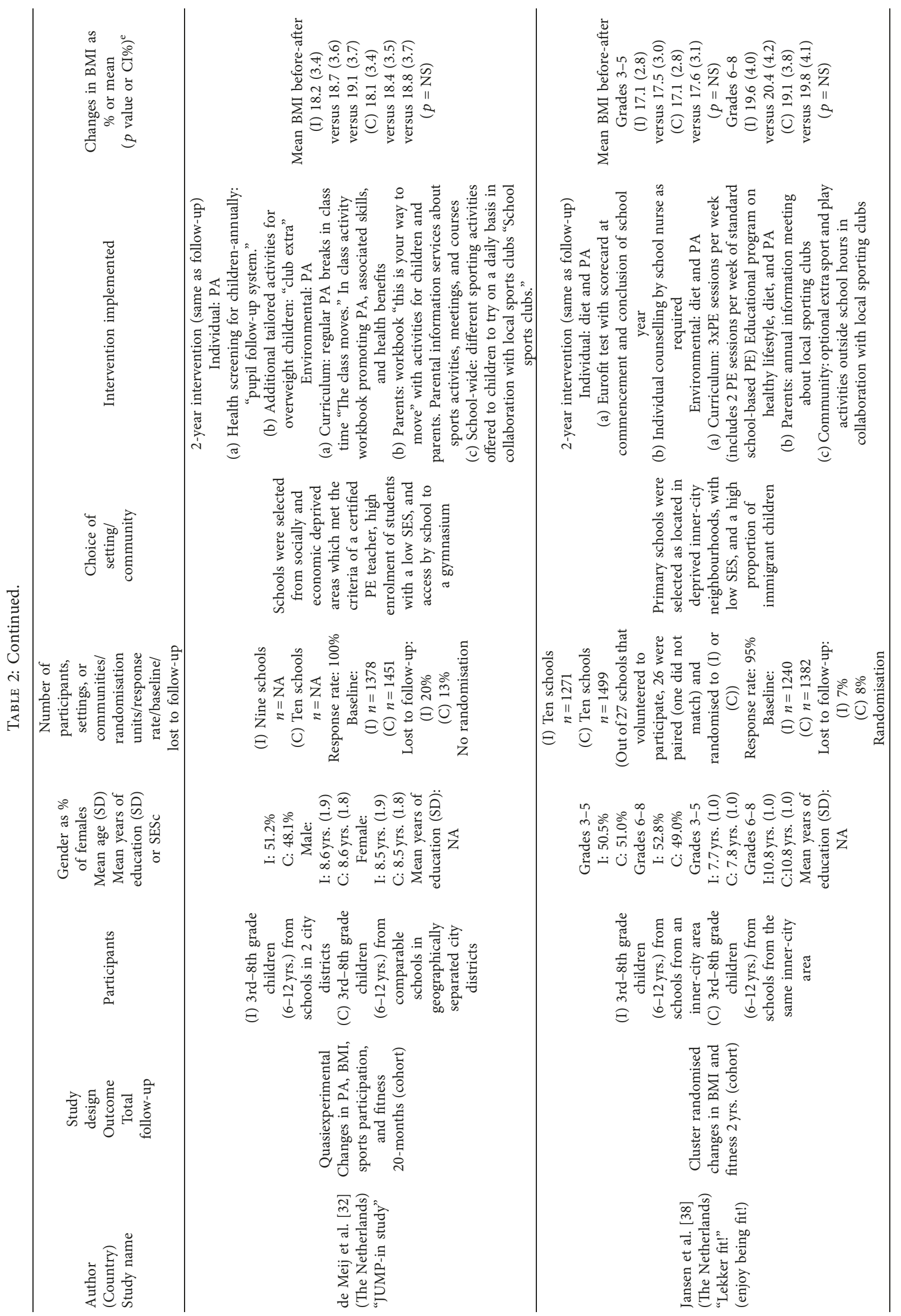




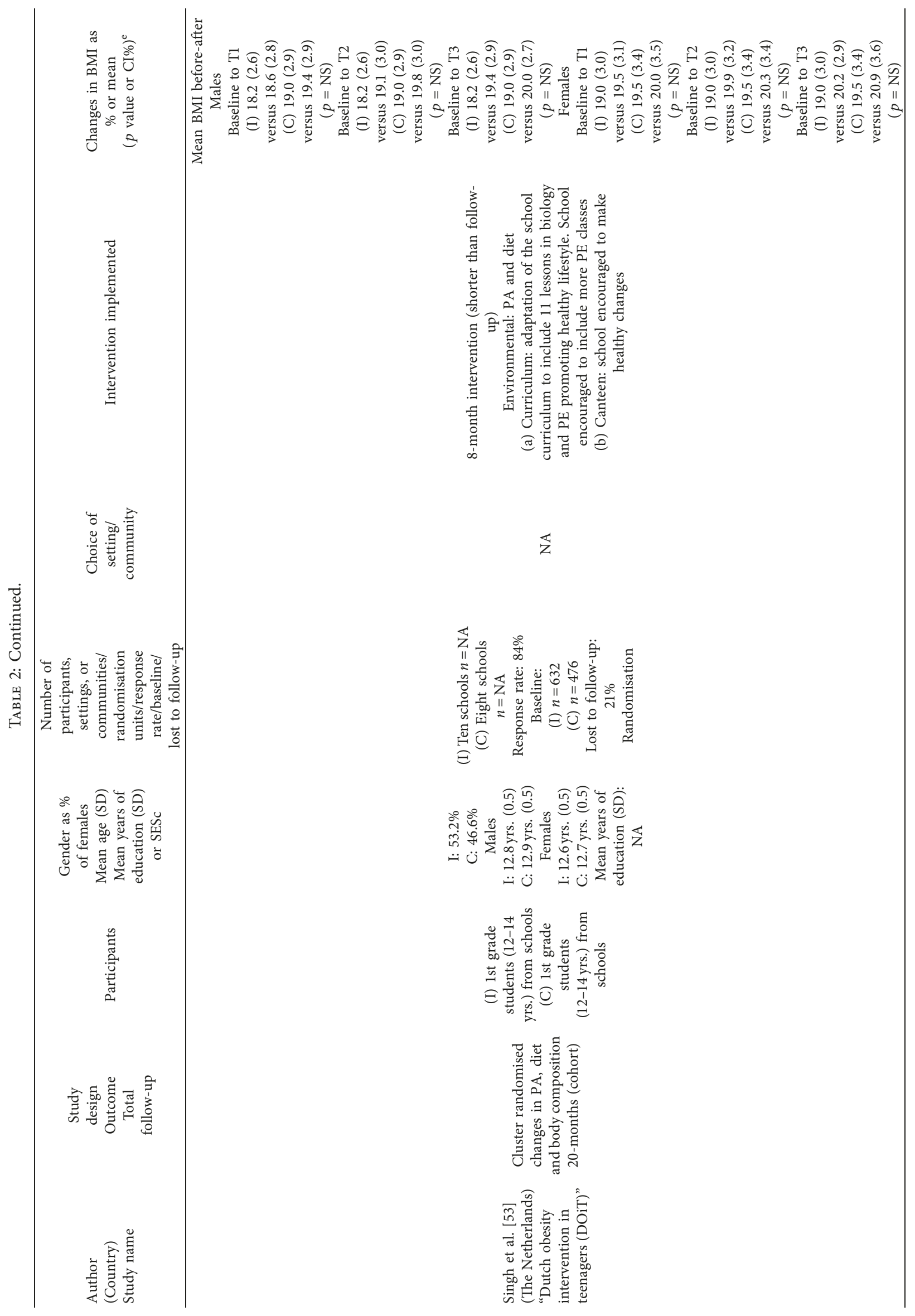




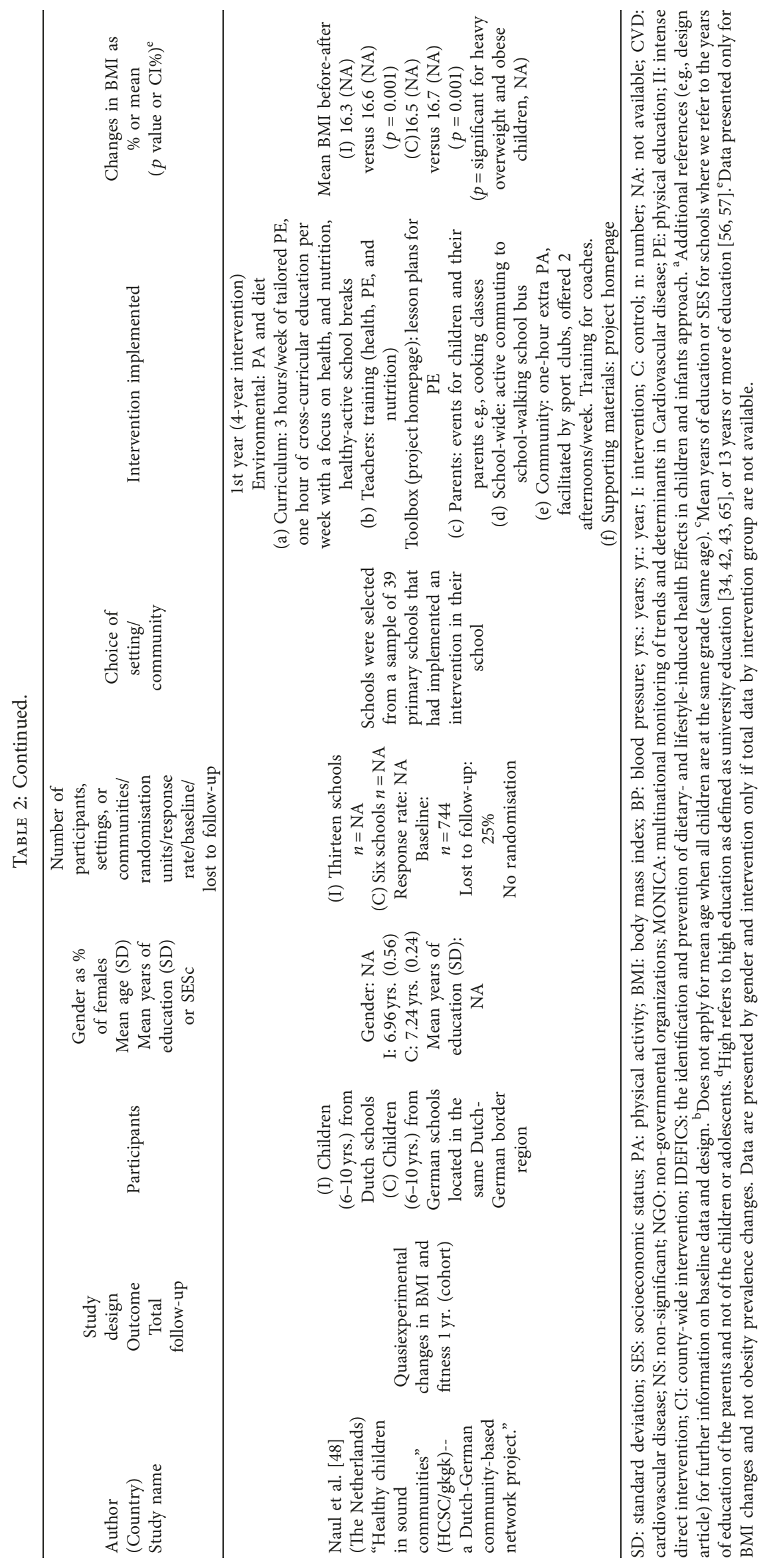




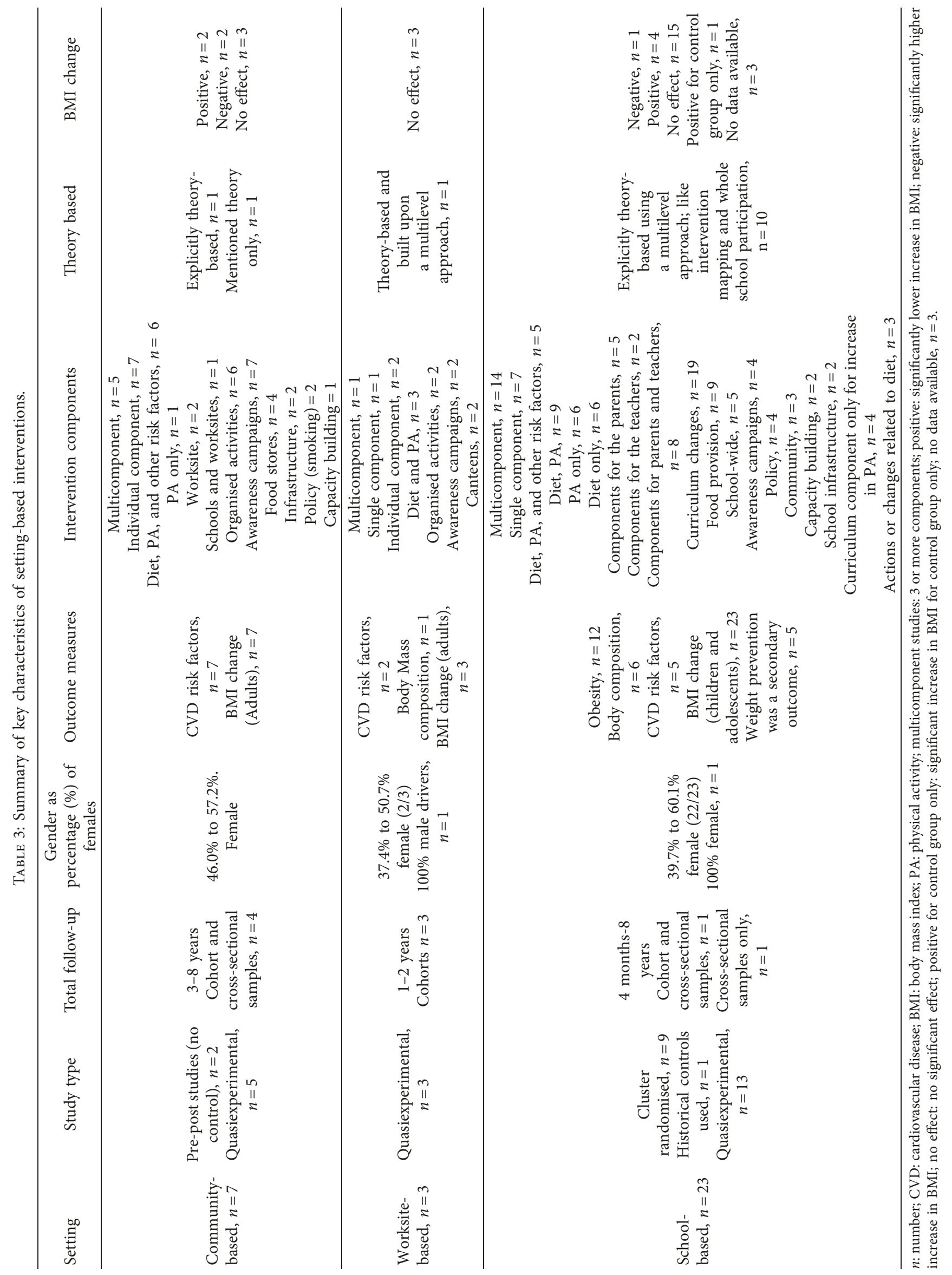


were cross-sectional samples taken for both I and C groups. Only the I group cohort for the study showed a decrease in BMI over time [56].

3.2. Worksite-Based Interventions. All three worksite-based interventions were quasiexperimental and measured BMI change for adults. The percentage of female participants in two of the studies was $37.4 \%$ to $50.7 \%$, whilst one intervention included $100 \%$ male drivers [36]. For one [36] of the 3 interventions, there was no information for either education level or SES of the participants. The duration of the total follow-up time varied from one to two years, and all were cohorts. Two interventions focused on CVD risk factors $[34,36]$ and one focused on body mass composition [43].

Two of the interventions had an individual component $[36,43]$ and one involved the families of the participants (educational sessions) [36]. One study was a multicomponent study [43] and one had only one component [36]. All three studies were interested in diet and PA [34, 36, 43]. Environmental components such as awareness campaigns were available in two studies $[34,43]$, canteens in two $[34,43]$, and organised activities in two studies $[36,43]$. One $[43,60]$ of the interventions was theory-based and built upon a multilevel approach, including setting and individual levels (data not shown). All three worksite-based interventions showed no differences in the changes for the I and $\mathrm{C}$ groups. One of the interventions showed a decrease in BMI in the I and C groups (not significant) but the differences for the I and $\mathrm{C}$ groups were not tested in this study [34]. In another study, there was a decrease in BMI in the I group but not in the C group [43].

3.3. School-Based Interventions. Nine of the school-based interventions were cluster randomised $[26,30,35,38,41$, $46,47,49,53$ ] and one used historical controls [29]. All other 13 studies were quasiexperimental $[24,25,27,28,31-33,40$, $48,50,51,54,55]$. One of the school-based interventions was performed around the Dutch-German borders [48], and one other school-based intervention performed in Sweden was part of a cross-cultural study among eight European countries [31]. In all studies, the control group was chosen from either the same or a neighbouring area, region, municipality, setting, or with a similar SES. Females accounted for $39.7 \%$ to $60.1 \%$ of participants in the school-based interventions, excluding one intervention which included $100 \%$ girls [55]. In 16 [24, 25, 27-30, 32, 38, 40, 41, $48,50,51,53-55]$ out of the 23 interventions, there was no information for either education level or SES of the participants or the parents of participants. All school-based interventions measured BMI change for children and adolescents. The duration of follow-up varied largely from four months to eight years. One study included both a cohort and cross-sectional samples [28] and one study included only cross-sectional samples [29]. Twelve interventions were focused on obesity [24-26, 30, 32, 38, 41, 47, 48, 54], six on body composition $[31,35,40,46,53,55]$, and the remaining five on CVD risk factors [27-29, 50, 51].
Fourteen school-based interventions were multicomponent studies [27-29, 31-33, 35, 38, 41, 46-50] and seven had only one component [24-26, 30, 51, 54, 55]. Five studies were interested in diet, PA, and other risk factors $[28,29,31,33,50]$ and nine in diet and PA [27, 35, $38,41,46-49,53]$. There were six studies interested in PA only [30, 32, 40, 51, 54, 55] and three interested in diet only [24-26]. Five school-based interventions were also focused on the parents $[28,29,31,32,38,41,47]$, two on the teachers' training [27, 40], and eight on both $[28,29,33,35$, 46, 48-50]. Environmental components such as curriculum changes were available in 19 studies [27-32, 35, 38, 40, $41,46-51,53-55]$, food provision in nine studies [24-26, $28,29,35,47,50,53]$, school-wide in five studies [31-33, $35,48]$, awareness campaigns in four studies [31, 33, 47, 50], policy in four studies, community in three studies $[31,38,48]$, capacity building in two $[28,29]$ and school infrastructure in two $[27,33]$. Finally, four school-based interventions had only a curriculum component for increase in PA [30, 51, 54, 55], whereas three school-based interventions had only actions or changes related to diet performed [24-26].

Ten $[31-33,35,38,41,46,48,49,53]$ of the 23 schoolbased interventions were explicitly theory-based using a multilevel approach: like intervention mapping and whole school participation (data not shown). Most of them did not show any differences in BMI changes between the I and $\mathrm{C}$ groups [25, 26, 30-33, 35, 38, 40, 41, 46, 50, 51, 53, 55]. In one study, there were only differences for one of the two schools [28] (different intervention for each school); in another study, there were no differences for 2 nd grade children [30] (however, no test for comparing the I and C groups was available in this study). One study showed a significantly higher increase in BMI in the I group compared to the $\mathrm{C}$ group [27]. Four studies showed a significantly lower increase in $\mathrm{BMI}$ in the $\mathrm{I}$ group compared to the $\mathrm{C}$ group $[28,30,35,48,54]$. Of these studies, one showed these differences only for females [35], one only for one of the two schools studied [28], and one only for 3rd grade children [30].

Finally, two studies showed a decrease in BMI in the I group [54] or in the I group for males but not for females [24]. Of these studies, Ask et al.'s study was the only study where there were no significant changes for the I group but there were for the C group [24] (however, no test for comparing the I and $\mathrm{C}$ groups was available in this study). Three studies did not have any available data as BMI mean or percent changes but changes in obesity rates. Therefore, they were excluded from comparisons [29, 47, 49].

3.4. Quality Assessment of Studies. Table 4 presents the quality assessment results of the included studies [24-56] with the use of supporting articles, where required $[57,59,65-68]$. None of the studies fulfilled all five criteria. There was only one study that fulfilled one criterion [39], 11 that fulfilled two [27-29, 31, 33, 44, 47, 48, 50, 51, 56], 14 that fulfilled three $[24,26,30,32,37,40-43,45,46,53-55]$, and seven that fulfilled four criteria [25, 34-36, 38, 49, 52]. Credibility of data collection instruments was the only 
TABLE 4: Quality assessment of setting-based interventions.

\begin{tabular}{|c|c|c|c|c|c|c|c|c|}
\hline Study & $\begin{array}{l}\text { Suitability } \\
\text { of study } \\
\text { design }\end{array}$ & $\begin{array}{l}\text { Number } \\
\text { of } \\
\text { criteria } \\
\text { met }\end{array}$ & Representativeness $^{\mathrm{b}}$ & Randomisation & Comparability $^{c}$ & $\begin{array}{c}\text { Credibility } \\
\text { of data } \\
\text { collection } \\
\text { instruments }\end{array}$ & $\begin{array}{l}\text { Attrition } \\
\text { rate }\end{array}$ & $\begin{array}{l}\text { Attributability } \\
\text { to } \\
\text { intervention }^{\mathrm{d}}\end{array}$ \\
\hline $\begin{array}{l}\text { Community-based } \\
\text { Jenum et al. [39] } \\
\text { Jenum et al. [59] }\end{array}$ & Category A & 1 & $\mathrm{NO}$ & $\mathrm{NO}$ & $\mathrm{NO}$ & YES & $\mathrm{NO}$ & $\mathrm{NO}$ \\
\hline $\begin{array}{l}\text { Lupton et al. [45] } \\
\text { Kumpusalo et al. }\end{array}$ & Category A & 3 & NA & $\mathrm{NO}$ & YES & YES & $\mathrm{NO}$ & YES \\
\hline $\begin{array}{l}{[42]} \\
\text { Kumpusalo et al. } \\
{[65]^{\mathrm{a}}}\end{array}$ & Category A & 3 & YES & $\mathrm{NO}$ & $\mathrm{NO}$ & YES & YES & NA \\
\hline Isacsson et al. [37] & Category B & 3 & YES & $\mathrm{E}$ & - & YES & YES & - \\
\hline $\begin{array}{l}\text { Lingfors et al. [44] } \\
\text { Weinehall et al. }\end{array}$ & $\begin{array}{c}\text { Category B } \\
\text { Category }\end{array}$ & 2 & $\mathrm{NO}$ & - & - & YES & YES & - \\
\hline $\begin{array}{l}{[56]} \\
\text { Brannstrom et al. } \\
{[57]^{\mathrm{a}}}\end{array}$ & $\begin{array}{l}\text { A/ } \\
\text { Category } \\
\text { B }\end{array}$ & 2 & YES & $\mathrm{NO}$ & NA & YES & $\mathrm{NO}$ & NA \\
\hline $\begin{array}{l}\text { Schuit et al. [52] } \\
\text { Worksite-based }\end{array}$ & Category A & 4 & YES & $\mathrm{NO}$ & YES & YES & YES & NA \\
\hline Engbers et al. [34] & Category A & 4 & $\mathrm{NO}$ & $\mathrm{NO}$ & YES & YES & YES & YES \\
\hline Kwak et al. [43] & Category A & 3 & $\mathrm{NO}$ & $\mathrm{NO}$ & YES & YES & YES & NA \\
\hline $\begin{array}{l}\text { Hedberg et al. } \\
{[36]} \\
\text { School-based }\end{array}$ & Category A & 4 & YES & $\mathrm{NO}$ & YES & YES & YES & YES \\
\hline Ask et al. [24] & Category A & 3 & NO (pilot study) & $\begin{array}{l}\text { YES (out of } \\
\text { two units) }\end{array}$ & YES & YES & NA & NA \\
\hline Ask et al. [25] & Category A & 4 & $\mathrm{NO}$ & $\begin{array}{l}\text { YES (out of } \\
\text { three units) }\end{array}$ & YES & YES & YES & NA \\
\hline Bere et al. [26] & Category A & 3 & YES & YES & NA & YES & $\mathrm{NO}$ & NA \\
\hline $\begin{array}{l}\text { Grydeland et al. } \\
\text { [35] }\end{array}$ & Category A & 4 & $\mathrm{NO}$ & YES & YES & YES & YES & NA \\
\hline Resaland et al. [51] & Category A & 2 & $\mathrm{NO}$ & $\mathrm{NO}$ & YES & YES & $\mathrm{NO}$ & NA \\
\hline Bugge et al. [27] & Category A & 2 & $\mathrm{NO}$ & $\mathrm{NO}$ & YES & YES & NO & NA \\
\hline Klakk et al. [40] & Category A & 3 & $\mathrm{NO}$ & $\mathrm{NO}$ & YES & YES & YES & NA \\
\hline Puska et al. [50] & Category A & 2 & $\mathrm{NO}$ & $\mathrm{NO}$ & NA & YES & YES & NA \\
\hline $\begin{array}{l}\text { Magnusson et al. } \\
\text { [46] }\end{array}$ & Category A & 3 & $\mathrm{NO}$ & YES & YES & YES & $\mathrm{NO}$ & NA \\
\hline $\begin{array}{l}\text { Elinder et al. [33] } \\
\text { Elinder et al. [66] }\end{array}$ & Category A & 2 & $\mathrm{NO}$ & $\mathrm{NO}$ & NA & YES & YES & NA \\
\hline Marcus et al. [47] & Category A & 2 & $\mathrm{NO}$ & YES & NA & YES & $\mathrm{NO}$ & $\mathrm{NA}$ \\
\hline Nyberg et al. [49] & Category A & 4 & $\mathrm{NO}$ & YES & YES & YES & YES & NA \\
\hline $\begin{array}{l}\text { De Henauw et al. } \\
\text { [31] } \\
\text { Hense et al. [67] }{ }^{\mathrm{a}} \\
\text { Ahrens et al. [68] }\end{array}$ & Category A & 2 & NA & $\mathrm{NO}$ & NA & YES & YES & NA \\
\hline $\begin{array}{l}\text { Sollerhed and } \\
\text { Ejlertsson [54] }\end{array}$ & Category A & 3 & $\mathrm{NO}$ & $\mathrm{NO}$ & YES & YES & YES & NA \\
\hline $\begin{array}{l}\text { Stenevi-Lundgren } \\
\text { et al. [55] }\end{array}$ & Category A & 3 & NO & $\mathrm{NO}$ & YES & YES & YES & NA \\
\hline Busch et al. [28] & Category A & 2 & NO & $\mathrm{NO}$ & YES & YES & $\mathrm{NO}$ & NA \\
\hline Busch et al. [29] & Category C & 2 & NO (pilot study) & $\mathrm{NO}$ & NA & YES & NA & YES \\
\hline de Greeff et al. [30] & Category A & 3 & NO & YES & YES & YES & NA & NA \\
\hline Kocken et al. [41] & Category A & 3 & $\mathrm{NO}$ & YES & YES & YES & $\mathrm{NO}$ & NA \\
\hline de Meij et al. [32] & Category A & 3 & $\mathrm{NO}$ & NO & YES & YES & YES & $\mathrm{NO}$ \\
\hline Jansen et al. [38] & Category A & 4 & NO & YES & YES & YES & YES & NA \\
\hline Singh et al. [53] & Category A & 3 & $\mathrm{NO}$ & YES & $\mathrm{NO}$ & YES & YES & NA \\
\hline Naul et al. [48] & Category A & 2 & $\mathrm{NO}$ & $\mathrm{NO}$ & $\mathrm{NO}$ & YES & YES & NA \\
\hline
\end{tabular}

NA: not available. ${ }^{a}$ Additional references (e.g., design article) for further information on baseline data and design. ${ }^{b}$ For the studies on schools, representativeness referred to the schools as units and not to the children/students participating. ${ }^{c}$ Baseline characteristics description or matching, if baseline BMI was not mentioned we considered Na. ${ }^{\mathrm{d}}$ Based on what is discussed or reported in the article, we did not consider NO in cases where I and C were in proximity, unless a possibility of contamination is discussed. ${ }^{\mathrm{e}}$ Does not apply, no control group. 
criterion that was fulfilled in all studies. Studies in which weight was self-reported $[26,28,29]$ were also considered to fulfil the criterion. For representativeness, six interventions fulfilled this criterion, of which four were whole of community [37, 42, 52, 56], one worksite [36], and one a schoolbased intervention [26]. For randomisation, only nine interventions were randomised and these were all schoolbased [26, 30, 35, 38, 41, 46, 47, 49, 53]. In addition, two interventions included a random allocation of intervention or control groups among two [24] or three schools [25]. For the comparability, two community $[45,52]$, all three worksite [34, 36, 43], and 15 school-based interventions fulfilled the criterion $[24,25,27,28,30,32,35,38$, $40,41,46,49,51,54,55]$. For the attrition rate, four whole of community [37, 42, 44, 52], all three worksite [34, 36, 43], and 13 school-based interventions fulfilled the criterion $[25,31-33,35,38,40,48-50,53-55]$. Finally, for the attributability to intervention (likely that the observed effects are attributable to the intervention and not due to a contamination of the control group or to a concurrent intervention), there was very little available discussed in the articles. Among the whole of community, one fulfilled [45] and one did not fulfil [39] this criterion, two worksite-based interventions $[34,36]$ and one school-based intervention [29] fulfilled, and one [32] did not fulfil this criterion.

\section{Discussion}

To our knowledge, this is the first systematic review focusing on setting-based interventions on obesity prevention in Nordic countries and the Netherlands, which includes all age groups and types of settings. Results for BMI change showed no consistent direction for whole of community interventions ( $2 / 7$ positive, $2 / 7$ negative, and $3 / 7$ no effect), no effect for worksite-based interventions (3/3), and no effect for many of the school-based interventions (1/23 negative, $3 / 23$ positive, 15/23 no effect, 1/23 BMI significant increase for control group only, and $3 / 23$ no data available). A quality appraisal showed that many studies poorly fulfilled criteria related to representativeness (25/33) and randomisation (20/33) or had no available information on attributability of the intervention (25/33). However, for comparability of baseline data (20/33) and attrition rates (20/33), evaluation was better.

Theoretical constructs are very important in research in general, for illustrating the associations between variables, the change process, and so on thus helping understand the interventions' mechanisms [69]. Especially in the field of behaviour change which is relevant to healthcare, ample work has been done in developing theories to guide studies. In this area, theory is very much needed and its value has often been underrecognised [70]. There are examples of interventions in obesity that showed results by using theory constructs' [71, 72].

Participatory interventions are also very important because they engage with people whose life-world and meaningful actions are under study. The target group should play a key role in planning, implementing, and adjusting the interventions. When constructing an intervention with a participatory dimension, it entails the mobilisation of people, feeling of empowerment, and self-efficacy. In the long run, this creates a better opportunity for sustainable solutions. The participatory research methods are geared towards planning and conducting the research process consequently, which means that the aim of the inquiry and the research questions develops out of the convergence of two perspectives: of science and of practice [73-75]. Research in the field of obesity has shown that participatory approaches are beneficial [76].

This systematic review illustrates that the studies in general used theory more as a background understanding, than for guiding the interventions, or for the discussion and interpretation of the results, and implications for further research. Several studies (18/33) did not use theory explicitly [24-27, 30, 34, 36, 37, 42, 44, 45, 47, 50-52, 54-56] and others used theories as the basis for choice of study design or approach $(3 / 33)[35,39,43]$. Some of the studies $(7 / 33)$ $[31,32,38,41,48,49,53]$ built on multicomponent and multilevel interventions such as intervention mapping (IM), socioecological theories or models, and models for individual behaviour; for example, theory of planned behaviour (TPB), social cognitive learning theory (SCT), and health belief model (HBM). Especially in the whole of community and schoolbased interventions, the background and theoretical frameworks were linked to theories of empowerment, participation, and whole-school participatory tailored approaches (5/33) $[28,29,33,40,46]$. Across the studies, there existed "a light way" of using theory. Theoretical framework was more often simply referred to, rather than something that was used concretely in problem formulation and as a basic structure in the studies. The lack of theoretical development and use in the field is an important finding. This can point to a greater need for the application of theory more specifically in future settingbased studies, thereby fulfilling the need for developing common standards and concrete theoretical basis for planning, implementing, and evaluating interventions within this field.

4.1. Whole of Community Interventions. The only available review on whole of community interventions on obesity [11] showed surprisingly that there are no available studies focusing primarily on obesity for adult populations. All of the whole of community interventions in our review had a broader scope, often targeting other risk factors for type 2 diabetes and CVD, beyond BMI. In addition, only one study [37] included a component on schools even though there were no measurements of change in risk factors for this young population. Although obesity is part of the causal pathway for these diseases, studies that do not primarily focus on obesity may risk having a weaker impact on BMI changes, due to the multiplicity of efforts directed towards other risk factors. Not only do other factors such as cholesterol, lipids, and blood glucose require a different timeframe to show meaningful changes, addressing alcohol and tobacco consumption also requires different strategies other than diet and PA.

Unfortunately, the vast majority of reviews on obesity and related risk factors are on children. We found only one 
systematic review [77] from 2003 on community-based interventions and type 2 diabetes that showed no significant improvements for BMI after intervention. Half of the whole of community interventions showed no change, and this did not seem to be related to a short duration of followup or to the use of a nonmulticomponent design. Other factors such as lack of complete implementation can explain the reduced impact in these studies. For two of these $[37,56]$, there was no information on implementation, and for one [42], full implementation was not achieved (problems with implementing PA due to lack of facilities and resistance to jogging) [42]. In addition, there was no information on implementation in the two studies that showed a favourable effect for BMI [39, 52]. However, in one of the studies [52], the authors considered that the reason for their success was the use of an integrative approach (participation of many actors such as organizations, sponsors, municipalities, etc.,) and the length of follow-up (five years).

Methodological issues can also reduce the strength of these studies and result in poor outcomes. One major issue is the use of a control group; without one, it is not possible to judge whether the changes are due to the project or due to other changes in that population. For the whole of community interventions, five were quasiexperimental. In addition, two of those used a cohort design, whereas the other three $[42,44,56]$ also used cross-sectional samples, which increase the variance compared to following the same individuals over time. Randomisation is another concern, and it was not used in any of the whole of community interventions. However, randomisation in this setting is often difficult to implement. A review that analysed the effect of randomisation on the heterogeneity of studies showed that randomisation does not introduce a serious bias [20]. However, in all of the studies, there was an effort to choose a control group with similar characteristics to the intervention group, such as SES or a similar or neighbouring community. Apparently, this was not enough to create comparable groups, since 2 studies $[45,52]$ had comparable characteristics at baseline and 2 studies did not $[39,42]$. Finally, attributability is a very important concern in health promotion studies due to possible 'contamination' or other interventions implemented during the study period. Surprisingly, most of the studies including whole of community did not discuss this possibility even though it can significantly affect the outcomes.

4.2. Worksite-Based Interventions. We were only able to detect three studies, where most of those excluded were studies that used individual counselling. The included studies focused largely on CVD risk factors, similarly to the whole of community interventions. It is very difficult to draw any conclusions from this limited number of studies. However, the results identify a clear need for more obesity prevention studies with an environmental component, implemented in the worksite setting. There were no changes in BMI observed in any of these interventions (3/3), and this might be partially due to relatively short follow-ups (one to two years) and no multicomponent studies, which usually reflect a serious effort for change in the environment. For example, in only one of the studies [36], support from the family was considered. On the other hand, all studies had a control group, who were cohorts, showed mostly attributability and comparability even though there was no randomisation process employed in any of them. It has to be noted that one of the studies [43] made an effort to use randomisation; however, there was enormous resistance from the different worksites to be randomly selected as controls (out of 128 randomly selected worksites, 12 were finally studied). This is an example showing that methodological weakness can arise despite an effort from the researcher's side.

A review by Maes et al. [78] which included two of our studies [36, 43] categorised these studies as "moderate quality," whereas many others were considered of "weak quality." The quality appraisal included important criteria such as prior analysis of the needs of the worksite, integration of the activities in the management practices and daily working life of the enterprise, and theory-based intervention development. The authors also argued that the inconclusive effects on BMI change were mostly due to the lack of sufficient and high-quality studies. However, another review [14] showed a moderate effect on BMI. None of the above reviews can be directly comparable to ours because they also included studies with an individual component (e.g., dietician counselling) which might have resulted in a positive effect for BMI, at least for the intervention duration.

4.3. School-Based Interventions. Most of the studies showed no effect for BMI (15/23). A meta-analysis by Waters [20] showed that interventions in schools were effective for BMI, particularly for children 6-12 years old, and these were similar to the whole of community interventions for children [11]. However, the authors mentioned that there should be caution due to the small study bias and heterogeneity in the studies. Interestingly, nine out of 23 of the school-based interventions in our review were small studies (maximum three schools as I or C group) $[24,25,28,29,46,50,51,54,55]$. An interesting observation was that all of the single component interventions were in schools, but one [54] showed no changes in BMI (6/7), suggesting that such an approach is very limited for changing outcomes such as BMI. From the reasons described for initiation of these studies, it seems that in most cases, they had a very narrow scope related to the specific needs of the school. The duration of the intervention however did not seem to be related to BMI changes.

In some of the studies [24,30,35], there was no change in BMI $(3 / 23)$ in the I group, and this is difficult to interpret. It would be tempting to consider this result as successful by suggesting that it stops the further BMI increase; however, there are other possibilities which actually do not reflect a successful programme: (1) there is no true effect or (2) ceiling effect because of normal weight of participants at baseline [35].

As for methodological issues, all school-based interventions were cohorts and had a control group but only 
nine were randomised studies. It is somehow reassuring that 15 studies showed comparability for baseline characteristics between I and $\mathrm{C}$ but that does not mean that studies should not use randomisation as a regular process. However, as mentioned previously, the process of randomisation is sometimes inhibited, as in one case where the schools participated only if they were considered as I schools [33]. Unfortunately, as for the other types of interventions, attributability was rarely discussed.

4.4. Limitations. Some major limitations of the articles included in our review are (1) very low reporting or discussion on attributability and SES, which is known to be associated with the effectiveness of a health promotion intervention, (2) unclear describing of results in some studies and some missing tests (comparison of changes in BMI between I and $\mathrm{C}$ which affected the way results are presented and possibly interpreted), and (3) reasons for choosing a region, municipality, worksite, or school such as practical (easy, already part of a project), with a very narrow scope in school-based interventions or initiation by local authorities which limit representativeness. Especially in the case of school-based interventions, representativeness was largely not fulfilled. However, in whole of community interventions, five were considered representative, showing most likely a more careful design view 'heaviness' of these projects.

All of the whole community studies included awareness campaigns but few components such as infrastructure and policies. For the schools, 19 studies made changes to the curriculum; however, fewer interventions incorporated: improved infrastructure, policies, and school-wide or community level strategies. These results show a seeming lack in creating a healthier environment through broader and vaster changes, which is considered a major component of a health promotion study. In addition, very few studies implemented or at least described a capacity building process. Across the included studies, there was "a light way" of using theory and theoretical frameworks; these were mostly only referred to, without describing if and how they were used to guide the studies, select tools or interpret the findings.

One limitation of our study was not being able to organise the studies by length of follow-up or type of intervention components. This was due to the heterogeneity of studies. However, if we had decided to restrict our studies based on follow-up time, we would have to exclude a significant amount of studies that provide valuable information. In addition, grouping based on follow-up would have created many subgroup categories especially for the community and worksite-based interventions.

\section{Conclusion}

This review has provided an overview of obesity prevention interventions in seven whole of community, three worksite and 23 school-based interventions, implemented in communities of Nordic countries and the Netherlands, where $\mathrm{BMI}$ was reported as an outcome. This review was unable to demonstrate associations with BMI outcomes among these settings. However, it is very difficult to distinguish whether these results are due to the heterogeneity of the study designs, or due to poor quality in terms of design or implementation. In addition, initiation of a project especially in the school setting was often motivated by a very narrow scope related to the schools' needs, and not by an effort to test comprehensive strategies for obesity prevention.

There is a need to prioritise interventions that include study designs of high quality, the use of theoretical constructs to guide the studies, and a participatory approach for optimal implementation and evaluation of obesity outcomes. Use of theory at all levels of an intervention as well as promoting participatory approaches have been acknowledged to improve the effectiveness of different types of interventions, including obesity. Some suggested criteria for 'good' theory in the area of behavioural change are: clarity of theoretical concepts, being explanatory, describing causality, testability, and so on. [79].

However, the future development of a published guideline on the complete, precise reporting of theory on different levels (process, implementation, and evaluation), even if possible in the obesity field, can help improve interventions. There are no explicit guidelines for settingbased interventions compared to clinical trials and interventions on diet and PA that focus on the individual. This leads to studies with no standard of quality based on defined criteria.

Guidelines should be created with an emphasis of criteria that can affect the study quality such as the ones we used in our review. An example of such criteria is a minimum period of follow-up based on evidence that shows how long it needs for obesity interventions to show a change in BMI, not factors such as political agendas. Another example is the consistent use of representative samples and randomisation as much as possible, instead of convenient and very small samples, especially for schools and worksites. Overall, it seems that presently there is not a serious commitment in preventing obesity through setting-based interventions and in particular in worksite interventions.

Commitment to further, more advanced research of settings-based interventions in these countries remains of vital importance, to secure and direct future investment for obesity prevention interventions.

\section{Conflicts of Interest}

The authors declare that they have no conflicts of interest.

\section{Acknowledgments}

This work was supported by Esbjerg Municipality, Denmark.

\section{References}

[1] World Health Organisation, Global Database on Body Mass Index, 2016.

[2] A. Stockmarr, T. Hejgaard, and J. Matthiessen, "Obesity prevention in the Nordic countries," Current Obesity Reports, vol. 5, no. 2, pp. 156-165, 2016. 
[3] T. Magnee, A. Burdorf, J. Brug et al., "Equity-specific effects of 26 Dutch obesity-related lifestyle interventions," American Journal of Preventive Medicine, vol. 44, no. 6, pp. e57-e66, 2013.

[4] G. Oen and K. M. Stormark, "Participatory action research in the implementing process of evidence-based intervention to prevent childhood obesity: project design of the "Healthy Future" study," Journal of Obesity, vol. 2013, Article ID 437206, 10 pages, 2013.

[5] L. De Mattia and S. L. Denney, "Childhood obesity prevention: successful community-based efforts," Annals of the American Academy of Political and Social Science, vol. 615, no. 1, pp. 83-99, 2008.

[6] S. L. Mayne, A. H. Auchincloss, and Y. L. Michael, "Impact of policy and built environment changes on obesity-related outcomes: a systematic review of naturally occurring experiments," Obesity Reviews, vol. 16, no. 5, pp. 362-375, 2015.

[7] G. R. McCormack and J. S. Virk, "Driving towards obesity: a systematized literature review on the association between motor vehicle travel time and distance and weight status in adults," Preventive Medicine, vol. 66, pp. 49-55, 2014.

[8] A. E. Bauman, R. S. Reis, J. F. Sallis, J. C. Wells, R. J. Loos, and B. W. Martin, "Correlates of physical activity: why are some people physically active and others not?," The Lancet, vol. 380, no. 9828 , pp. 258-271, 2012.

[9] World Health Organisation, Finland curbs childhood obesity by integrating health in all policies, 2015.

[10] Y. Wang, L. Cai, Y. Wu et al., "What childhood obesity prevention programmes work? A systematic review and metaanalysis," Obesity Reviews, vol. 16, no. 7, pp. 547-565, 2015.

[11] L. Wolfenden, R. Wyse, M. Nichols, S. Allender, L. Millar, and P. McElduff, "A systematic review and meta-analysis of whole of community interventions to prevent excessive population weight gain," Preventive Medicine, vol. 62, pp. 193-200, 2014.

[12] G. Mura, N. B. Rocha, I. Helmich et al., "Physical activity interventions in schools for improving lifestyle in European countries," Clinical Practice and Epidemiology in Mental Health, vol. 11, no. 1, pp. 77-101, 2015.

[13] W. J. Bemelmans, T. M. Wijnhoven, M. Verschuuren, and J. Breda, "Overview of 71 European community-based initiatives against childhood obesity starting between 2005 and 2011: general characteristics and reported effects," BMC Public Health, vol. 14, no. 1, p. 758, 2014.

[14] L. M. Anderson, T. A. Quinn, K. Glanz et al., "The effectiveness of worksite nutrition and physical activity interventions for controlling employee overweight and obesity: a systematic review," American Journal of Preventive Medicine, vol. 37, no. 4, pp. 340-357, 2009.

[15] S. Torp, L. Eklund, and S. Thorpenberg, "Research on workplace health promotion in the Nordic countries: a literature review, 1986-2008," Global Health Promotion, vol. 18, no. 3, pp. 15-22, 2011.

[16] S. Torp and H. F. Vinje, "Is workplace health promotion research in the Nordic countries really on the right track?," Scandinavian Journal of Public Health, vol. 42, no. 15, pp. 74-81, 2014.

[17] P. Craig, P. Dieppe, S. Macintyre, S. Michie, I. Nazareth, and M. Petticrew, "Developing and evaluating complex interventions: the new Medical Research Council guidance," British Medical Journal, vol. 337, p. a1655, 2008.

[18] D. Moher, A. Liberati, J. Tetzlaff, and D. G. Altman, "Preferred reporting items for systematic reviews and meta-analyses: the PRISMA statement," Journal of Clinical Epidemiology, vol. 62, no. 10, pp. 1006-1012, 2009.
[19] R. H. Cox, "The social construction of an imperative: why welfare reform happened in Denmark and the Netherlands but not in Germany," World Politics, vol. 53, no. 3, pp. 463-498, 2001.

[20] E. Waters, A. de Silva-Sanigorski, B. J. Burford et al., "Interventions for preventing obesity in children," Cochrane Database of Systematic Reviews, vol. 12, no. 3, p. CD001871, 2011.

[21] A. A. Atienza and A. C. King, "Community-based health intervention trials: an overview of methodological issues," Epidemiologic Reviews, vol. 24, no. 1, pp. 72-79, 2002.

[22] S. D. Golden and J. A. Earp, "Social ecological approaches to individuals and their contexts: twenty years of health education \& behavior health promotion interventions," Health Education and Behavior, vol. 39, no. 3, pp. 364-372, 2012.

[23] D. Ogilvie, D. Fayter, M. Petticrew et al., "The harvest plot: a method for synthesising evidence about the differential effects of interventions," BMC Medical Research Methodology, vol. 8, no. 1, p. 8, 2008 .

[24] A. S. Ask, S. Hernes, I. Aarek, G. Johannessen, and M. Haugen, "Changes in dietary pattern in 15 year old adolescents following a 4 month dietary intervention with school breakfast-a pilot study," Nutrition Journal, vol. 5, no. 1, p. 33, 2006.

[25] A. S. Ask, S. Hernes, I. Aarek, F. Vik, C. Brodahl, and M. Haugen, "Serving of free school lunch to secondary-school pupils-a pilot study with health implications," Public Health Nutrition, vol. 13, no. 2, pp. 238-244, 2010.

[26] E. Bere, K. I. Klepp, and N. C. Overby, "Free school fruit: can an extra piece of fruit every school day contribute to the prevention of future weight gain? A cluster randomized trial," Food and Nutrition Research, vol. 58, no. 1, p. 23194, 2014.

[27] A. Bugge, B. El-Naaman, M. Dencker et al., "Effects of a threeyear intervention: the Copenhagen school child intervention study," Medicine and Science in Sports and Exercise, vol. 44, no. 7, pp. 1310-1317, 2012.

[28] V. Busch, J. R. De Leeuw, N. P. Zuithoff, T. A. Van Yperen, and A. J. Schrijvers, "A controlled health promoting school study in the Netherlands: effects after 1 and 2 years of intervention," Health Promotion Practice, vol. 16, no. 4, pp. 592-600, 2015.

[29] V. Busch, R. J. De Leeuw, and A. J. Schrijvers, "Results of a multibehavioral health-promoting school pilot intervention in a Dutch secondary school," Journal of Adolescent Health, vol. 52, no. 4, pp. 400-406, 2013.

[30] J. W. de Greeff, E. Hartman, M. J. Mullender-Wijnsma, R. J. Bosker, S. Doolaard, and C. Visscher, "Effect of physically active academic lessons on body mass index and physical fitness in primary school children," Journal of School Health, vol. 86, no. 5, pp. 346-352, 2016.

[31] S. De Henauw, I. Huybrechts, I. De Bourdeaudhuij et al., "Effects of a community-oriented obesity prevention programme on indicators of body fatness in preschool and primary school children. Main results from the IDEFICS study," Obesity Reviews, vol. 16, pp. 16-29, 2015.

[32] J. S. de Meij, M. J. Chinapaw, M. M. van Stralen, M. F. van der Wal, L. van Dieren, and W. van Mechelen, "Effectiveness of JUMP-in, a Dutch primary school-based community intervention aimed at the promotion of physical activity," British Journal of Sports Medicine, vol. 45, no. 13, pp. 10521057, 2011.

[33] L. S. Elinder, N. Heinemans, J. Hagberg, A. K. Quetel, and M. Hagstromer, "A participatory and capacity-building approach to healthy eating and physical activity- SCIP-school: 
a 2-year controlled trial," International Journal of Behavioral Nutrition and Physical Activity, vol. 9, no. 1, p. 145, 2012.

[34] L. H. Engbers, M. N. van Poppel, and W. van Mechelen, "Modest effects of a controlled worksite environmental intervention on cardiovascular risk in office workers," Preventive Medicine, vol. 44, no. 4, pp. 356-362, 2007.

[35] M. Grydeland, M. Bjelland, S. A. Anderssen et al., "Effects of a 20-month cluster randomised controlled school-based intervention trial on BMI of school-aged boys and girls: the HEIA study," British Journal of Sports Medicine, vol. 48, no. 9, pp. 768-773, 2014.

[36] G. E. Hedberg, L. Wikstrom-Frisen, and U. Janlert, "Comparison between two programmes for reducing the levels of risk indicators of heart diseases among male professional drivers," Occupational and Environmental Medicine, vol. 55, no. 8, pp. 554-561, 1998.

[37] A. Isacsson, L. H. Lindholm, B. Schersten et al., "Community intervention against non-insulin dependent diabetes mellitus (NIDDM) and cardiovascular disease: a study based on Swedish health care," Cardiovascular Risk Factors, vol. 6, pp. 164-171, 1996.

[38] W. Jansen, G. Borsboom, A. Meima et al., "Effectiveness of a primary school-based intervention to reduce overweight," International Journal of Pediatric Obesity, vol. 6, no. 2, pp. e70-e77, 2011.

[39] A. K. Jenum, S. A. Anderssen, K. I. Birkeland et al., "Promoting physical activity in a low-income multiethnic district: effects of a community intervention study to reduce risk factors for type 2 diabetes and cardiovascular disease: a community intervention reducing inactivity," Diabetes Care, vol. 29, no. 7, pp. 1605-1612, 2006.

[40] H. Klakk, M. Chinapaw, M. Heidemann, L. B. Andersen, and N. Wedderkopp, "Effect of four additional physical education lessons on body composition in children aged 8-13 years-a prospective study during two school years," BMC Pediatrics, vol. 13, no. 1, p. 170, 2013.

[41] P. L. Kocken, A. M. Scholten, E. Westhoff, B. P. De Kok, E. M. Taal, and R. A. Goldbohm, "Effects of a theory-based education program to prevent overweightness in primary school children," Nutrients, vol. 8, no. 12, p. 12, 2016.

[42] E. Kumpusalo, L. Neittaanmaki, P. Halonen, H. Pekkarinen, I. Penttila, and M. Parviainen, "Finnish healthy village study: impact and outcomes of a low-cost local health promotion programme," Health Promotion International, vol. 11, no. 2, pp. 105-115, 1996.

[43] L. Kwak, S. P. Kremers, M. J. Candel, T. L. Visscher, J. Brug, and M. A. van Baak, "Changes in skinfold thickness and waist circumference after 12 and 24 months resulting from the NHF-NRG in balance-project," International Journal of Behavioral Nutrition and Physical Activity, vol. 7, no. 1, p. 26, 2010.

[44] H. Lingfors, K. Lindstrom, L. G. Persson, C. Bengtsson, and L. Lissner, "Evaluation of "Live for Life" a health promotion programme in the County of Skaraborg, Sweden," Journal of Epidemiology and Community Health, vol. 55, no. 4, pp. 277-282, 2001.

[45] B. S. Lupton, V. Fonnebo, A. J. Sogaard, and S. Finnmark Intervention, "The Finnmark intervention study: is it possible to change CVD risk factors by community-based intervention in an Arctic village in crisis?," Scandinavian Journal of Public Health, vol. 31, no. 3, pp. 178-186, 2003.

[46] K. T. Magnusson, H. Hrafnkelsson, I. Sigurgeirsson, E. Johannsson, and T. Sveinsson, "Limited effects of a 2-year school-based physical activity intervention on body composition and cardiorespiratory fitness in 7-year-old children," Health Education Research, vol. 27, no. 3, pp. 484-494, 2012.

[47] C. Marcus, G. Nyberg, A. Nordenfelt, M. Karpmyr, J. Kowalski, and U. A. Ekelund, "A 4-year, cluster-randomized, controlled childhood obesity prevention study: STOPP," International Journal of Obesity, vol. 33, no. 4, pp. 408-417, 2009.

[48] R. Naul, D. Schmelt, D. Dreiskaemper, D. Hoffmann, and M. l'Hoir, "Healthy children in sound communities' (HCSC/gkgk)-a Dutch-German community-based network project to counteract obesity and physical inactivity," Family Practice, vol. 29, no. 1, pp. i110-i116, 2012.

[49] G. Nyberg, E. Sundblom, A. Norman, B. Bohman, J. Hagberg, and L. S. Elinder, "Effectiveness of a universal parental support programme to promote healthy dietary habits and physical activity and to prevent overweight and obesity in 6year-old children: the Healthy School Start Study, a clusterrandomised controlled trial," PLoS One, vol. 10, no. 2, article e0116876, 2015.

[50] P. Puska, E. Vartiainen, U. Pallonen et al., "The North Karelia youth project: evaluation of two years of intervention on health behavior and CVD risk factors among 13- to 15-year old children," Preventive Medicine, vol. 11, no. 5, pp. 550-570, 1982.

[51] G. K. Resaland, S. A. Anderssen, I. M. Holme, A. Mamen, and L. B. Andersen, "Effects of a 2-year school-based daily physical activity intervention on cardiovascular disease risk factors: the Sogndal school-intervention study," Scandinavian Journal of Medicine and Science in Sports, vol. 21, no. 6, pp. e122-e131, 2011.

[52] A. J. Schuit, G. C. Wendel-Vos, W. M. Verschuren et al., "Effect of 5-year community intervention Hartslag Limburg on cardiovascular risk factors," American Journal of Preventive Medicine, vol. 30, no. 3, pp. 237-242, 2006.

[53] A. S. Singh, A. P. M. J. Chin, J. Brug, and W. van Mechelen, "Dutch obesity intervention in teenagers: effectiveness of a school-based program on body composition and behavior," Archives of Pediatrics and Adolescent Medicine, vol. 163, no. 4, pp. 309-317, 2009.

[54] A. C. Sollerhed and G. Ejlertsson, "Physical benefits of expanded physical education in primary school: findings from a 3-year intervention study in Sweden," Scandinavian Journal of Medicine and Science in Sports, vol. 18, no. 1, pp. 102-107, 2008.

[55] S. Stenevi-Lundgren, R. M. Daly, C. Linden, P. Gardsell, and M. K. Karlsson, "Effects of a daily school based physical activity intervention program on muscle development in prepubertal girls," European Journal of Applied Physiology, vol. 105, no. 4, pp. 533-541, 2009.

[56] L. Weinehall, G. Westman, G. Hellsten et al., "Shifting the distribution of risk: results of a community intervention in a Swedish programme for the prevention of cardiovascular disease," Journal of Epidemiology and Community Health, vol. 53, no. 4, pp. 243-250, 1999.

[57] I. Brannstrom, L. Weinehall, L. A. Persson, P. O. Wester, and S. Wall, "Changing social patterns of risk factors for cardiovascular disease in a Swedish community intervention programme," International Journal of Epidemiology, vol. 22, no. 6, pp. 1026-1037, 1993.

[58] J. S. De Meij, M. J. Chinapaw, S. P. Kremers, M. F. Van der Wal, M. E. Jurg, and W. Van Mechelen, "Promoting physical activity in children: the stepwise development of the primary school-based JUMP-in intervention applying the RE-AIM evaluation framework," British Journal of Sports Medicine, vol. 44, no. 12, pp. 879-887, 2010. 
[59] A. K. Jenum, C. Lorentzen, S. A. Anderssen et al., "Promoting physical activity in a multi-ethnic district-methods and baseline results of a pseudo-experimental intervention study," European Journal of Cardiovascular Prevention and Rehabilitation, vol. 10, no. 5, pp. 387-396, 2003.

[60] L. Kwak, S. P. Kremers, A. Werkman, T. L. Visscher, M. A. van Baak, and J. Brug, "The NHF-NRG in balanceproject: the application of intervention mapping in the development, implementation and evaluation of weight gain prevention at the worksite," Obesity Reviews, vol. 8, no. 4, pp. 347-361, 2007.

[61] N. Lien, M. Bjelland, I. H. Bergh et al., "Design of a 20-month comprehensive, multicomponent school-based randomised trial to promote healthy weight development among 11-13 year olds: the Health in Adolescents study," Scandinavian Journal of Public Health, vol. 38, no. 5, pp. 38-51, 2010.

[62] K. T. Magnusson, I. Sigurgeirsson, T. Sveinsson, and E. Johannsson, "Assessment of a two-year school-based physical activity intervention among 7-9-year-old children," International Journal of Behavioral Nutrition and Physical Activity, vol. 8, no. 1, pp. 1-13, 2011.

[63] I. Pigeot, T. Baranowski, and S. De Henauw, "The IDEFICS intervention trial to prevent childhood obesity: design and study methods," Obesity Reviews, vol. 16, no. 2, pp. 4-15, 2015.

[64] A. S. Singh, A. P. M. J. Chin, S. P. Kremers, T. L. Visscher, J. Brug, and W. van Mechelen, "Design of the Dutch obesity intervention in teenagers (NRG-DOiT): systematic development, implementation and evaluation of a school-based intervention aimed at the prevention of excessive weight gain in adolescents," BMC Public Health, vol. 6, no. 1, p. 304, 2006.

[65] E. Kumpusalo, L. Neittaanmäki, H. Pekkarinen et al., "Finnish healthy village study: health profile analysis for local health promotion," Health Promotion International, vol. 6, no. 1, pp. 3-12, 1991.

[66] L. S. Elinder, N. Heinemans, Z. Zeebari, and E. Patterson, "Longitudinal changes in health behaviours and body weight among Swedish school children-associations with age, gender and parental education-the SCIP school cohort," BMC Public Health, vol. 14, no. 1, p. 640, 2014.

[67] S. Hense, H. Pohlabeln, N. Michels et al., "Determinants of attrition to follow-up in a multicentre cohort study in children-results from the IDEFICS study," Epidemiology Research International, vol. 2013, Article ID 936365, 9 pages, 2013.

[68] W. Ahrens, K. Bammann, A. Siani et al., "The IDEFICS cohort: design, characteristics and participation in the baseline survey," International Journal of Obesity, vol. 35, no. 1, pp. S3-S15, 2011.

[69] D. E. Patton, C. M. Hughes, C. A. Cadogan, and C. A. Ryan, "Theory-based interventions to improve medication adherence in older adults prescribed polypharmacy: a systematic review," Drugs and Aging, vol. 34, no. 2, pp. 97-113, 2017.

[70] F. Davidoff, M. Dixon-Woods, L. Leviton, and S. Michie, "Demystifying theory and its use in improvement," $B M J$ Quality and Safety, vol. 24, no. 3, pp. 228-238, 2015.

[71] H. Beckman, S. Hawley, and T. Bishop, "Application of theory-based health behavior change techniques to the prevention of obesity in children," Journal of Pediatric Nursing, vol. 21, no. 4, pp. 266-275, 2006.

[72] J. J. Lloyd, S. Logan, C. J. Greaves, and K. M. Wyatt, "Evidence, theory and context-using intervention mapping to develop a school-based intervention to prevent obesity in children," International Journal of Behavioral Nutrition and Physical Activity, vol. 8, no. 1, p. 73, 2011.
[73] B. L. Hall, "Participatory research, popular knowledge and power: a personal reflection," Convergence: An International Journal of Adult Education, vol. 14, pp. 6-19, 1981.

[74] J. E. Ritchie, "Criteria and checkpoints for better community health promotion," Promotion and Education, vol. 14, no. 2, pp. 96-97, 2007.

[75] S. Nishtar, M. Akerman, M. Amuyunzu-Nyamongo et al., "The statement of the global consortium on community health promotion," Promotion and Education, vol. 13, no. 1, pp. 5-6, 2006.

[76] C. Economos and S. Blondin, "Obesity interventions in the community: engaged and participatory approaches," Current Obesity Reports, vol. 3, no. 2, pp. 199-205, 2014.

[77] D. W. Satterfield, M. Volansky, C. J. Caspersen et al., "Community-based lifestyle interventions to prevent type 2 diabetes," Diabetes Care, vol. 26, no. 9, pp. 2643-2652, 2003.

[78] L. Maes, E. Van Cauwenberghe, W. Van Lippevelde et al., "Effectiveness of workplace interventions in Europe promoting healthy eating: a systematic review," European Journal of Public Health, vol. 22, no. 5, pp. 677-683, 2012.

[79] S. Michie, R. West, R. Campbell, J. Brown, and H. Gainforth, An $A B C$ of Behaviour Change Theories, Silverback Publishing, London, UK, 2014. 


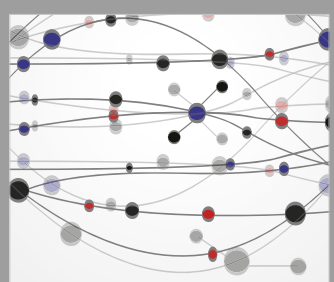

The Scientific World Journal
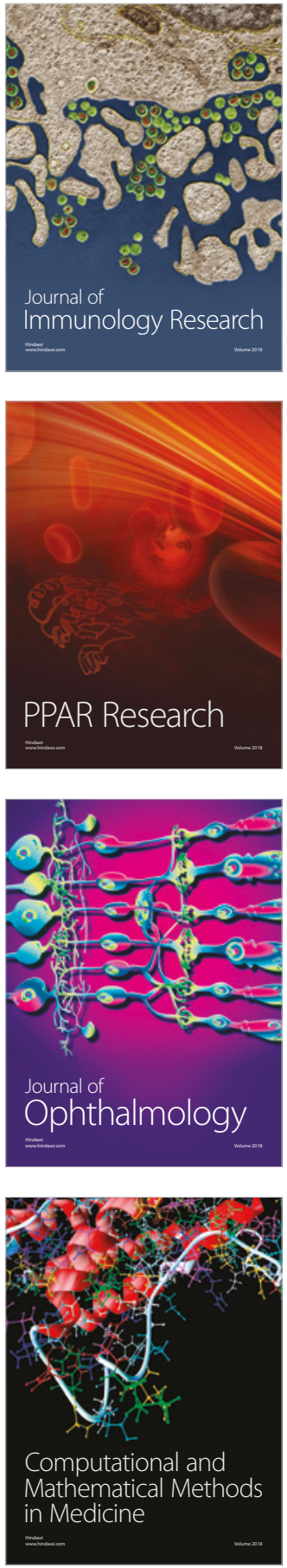

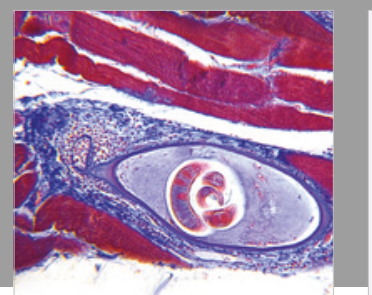

Gastroenterology Research and Practice

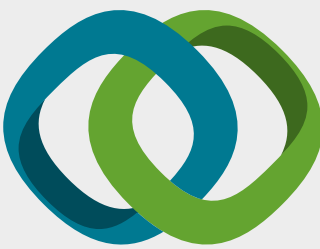

\section{Hindawi}

Submit your manuscripts at

www.hindawi.com
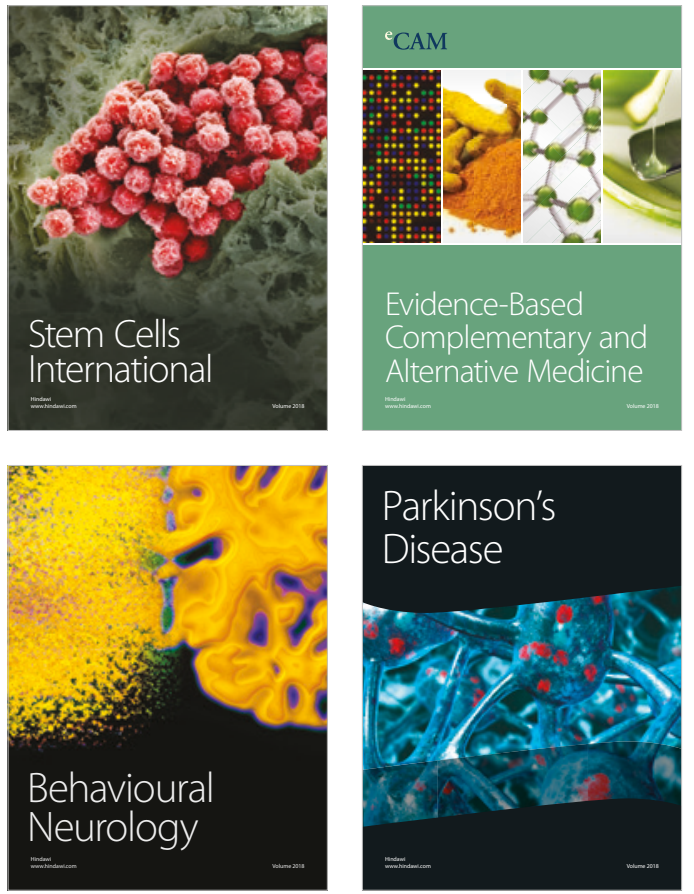

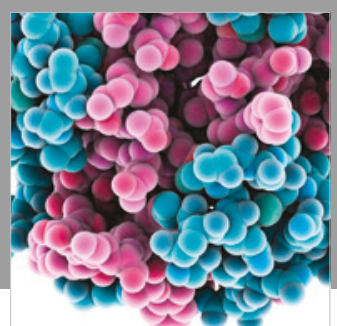

ournal of

Diabetes Research

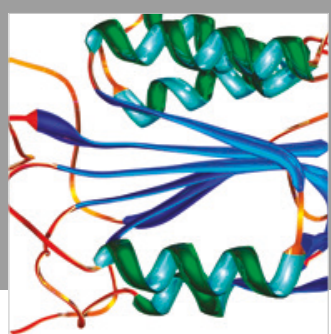

Disease Markers
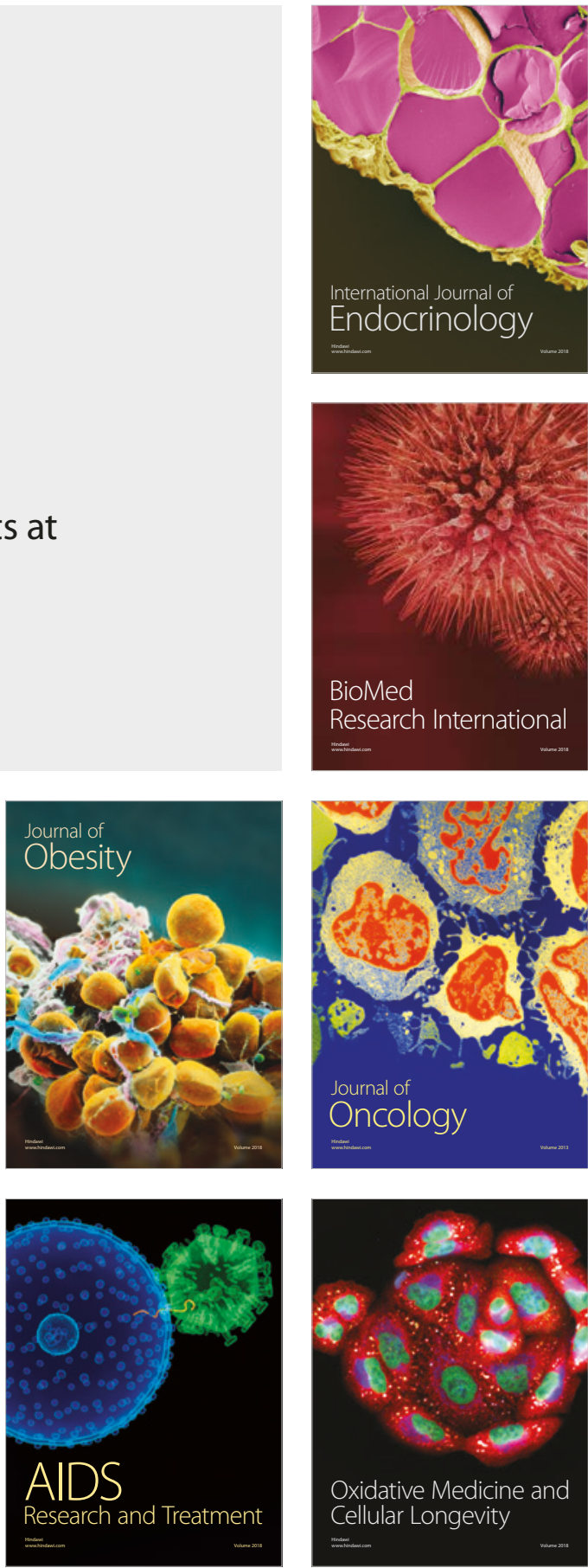